\title{
Single Particle Soot Photometer intercomparison at the AIDA chamber
}

\author{
M. Laborde ${ }^{1, *}$, M. Schnaiter ${ }^{2}$, C. Linke ${ }^{2}$, H. Saathoff ${ }^{2}$, K.-H. Naumann ${ }^{2}$, O. Möhler ${ }^{2}$, S. Berlenz ${ }^{3}$, U. Wagner ${ }^{3}$, \\ J. W. Taylor ${ }^{4}$, D. Liu ${ }^{4}$, M. Flynn ${ }^{4}$, J. D. Allan ${ }^{4,5}$, H. Coe ${ }^{4}$, K. Heimerl ${ }^{6}$, F. Dahlkötter ${ }^{6}$, B. Weinzierl ${ }^{6}$, A. G. Wollny ${ }^{7, * *}$, \\ M. Zanatta ${ }^{8}$, J. Cozic ${ }^{8}$, P. Laj ${ }^{8}$, R. Hitzenberger ${ }^{9}$, J. P. Schwarz ${ }^{10}$, and M. Gysel ${ }^{1}$ \\ ${ }^{1}$ Laboratory of Atmospheric Chemistry, Paul Scherrer Institute, 5232 Villigen PSI, Switzerland \\ ${ }^{2}$ Institute for Meteorology and Climate Research, Atmospheric Aerosol Research, Karlsruhe Institute of Technology, \\ Karlsruhe, Germany \\ ${ }^{3}$ Institut für Kolbenmaschinen, Karlsruhe Institute of Technology, Karlsruhe, Germany \\ ${ }^{4}$ School of Earth, Atmospheric and Environmental Sciences, The University of Manchester, Manchester, UK \\ ${ }^{5}$ National Centre for Atmospheric Science, The University of Manchester, Manchester, UK \\ ${ }^{6}$ Deutsches Zentrum für Luft- und Raumfahrt, Institut für Physik der Atmosphäre, Oberpfaffenhofen, Germany \\ ${ }^{7}$ Biogeochemistry Department, Max Planck Institute for Chemistry, Mainz, Germany \\ ${ }^{8}$ Laboratoire de Glaciologie et Géophysique de l'Environnement, Saint-Martin d'Hères, France \\ ${ }^{9}$ Fakultät für Physik, Universität Wien, Austria \\ ${ }^{10}$ Earth System Research Laboratory, NOAA, Boulder, CO, USA \\ *now at: AerosolConsultingML GmbH, Switzerland \\ ** now at: Deutscher Wetterdienst, Offenbach, Germany
}

Correspondence to: M. Gysel (martin.gysel@psi.ch)

Received: 25 April 2012 - Published in Atmos. Meas. Tech. Discuss.: 14 May 2012

Revised: 9 November 2012 - Accepted: 15 November 2012 - Published: 20 December 2012

\begin{abstract}
Soot particles, consisting of black carbon (BC), organic carbon (OC), inorganic salts, and trace elements, are emitted into the atmosphere during incomplete combustion. Accurate measurements of atmospheric BC are important as BC particles cause adverse health effects and impact the climate.

Unfortunately, the accurate measurement of the properties and mass concentrations of $\mathrm{BC}$ particles remains difficult. The Single Particle Soot Photometer (SP2) can contribute to improving this situation by measuring the mass of refractory $\mathrm{BC}$ in individual particles as well as its mixing state.

Here, the results of the first detailed SP2 intercomparison, involving 6 SP2s from 6 different research groups, are presented, including the most evolved data products that can presently be calculated from SP2 measurements.

It was shown that a detection efficiency of almost $100 \%$ down to $1 \mathrm{fg} \mathrm{BC}$ per particle can readily be achieved, and that this limit can be pushed down to $\sim 0.2 \mathrm{fg} \mathrm{BC}$ with optimal SP2 setup. Number and mass size distributions of BC cores
\end{abstract}

agreed within $\pm 5 \%$ and $\pm 10 \%$, respectively, in between the SP2s, with larger deviations in the range below $1 \mathrm{fg} \mathrm{BC}$.

The accuracy of the SP2's mass concentration measurement depends on the calibration material chosen. The SP2 has previously been shown to be equally sensitive to fullerene soot and ambient BC from sources where fossil fuel was dominant and less sensitive to fullerene soot than to Aquadag. Fullerene soot was therefore chosen as the standard calibration material by the SP2 user community; however, many data sets rely solely on Aquadag calibration measurements. The difference in SP2 sensitivity was found to be almost equal (fullerene soot to Aquadag response ratio of $\sim 0.75$ at $8.9 \mathrm{fg} \mathrm{BC}$ ) for all SP2s. This allows the calculation of a fullerene soot equivalent calibration curve from a measured Aquadag calibration, when no fullerene soot calibration is available. It could be shown that this approach works well for all SP2s over the mass range of 1-10 fg. This range is suitable for typical BC mass size distributions in the ambient air far from sources. 
The number size distribution of purely scattering particles optically measured by the 6 SP2s also agreed within $15 \%$. Measurements of the thickness of non-refractory coatings (i.e. product from $\alpha$-pinene ozonolysis) on the $\mathrm{BC}$ particles, relying on $\mathrm{BC}$ mass optical size and on an additional particle position measurement, also compared well (within $\pm 17 \%)$. The estimated coating thickness values were consistent with thermo-optical analysis of OC and elemental carbon (EC) content, though absolutely accurate values cannot be expected given all the assumptions that have to be made regarding refractive index, particle morphology, etc.

This study showed that the SP2 provides accurate and reproducible data, but also that high data quality is only achieved if the SP2 is carefully tuned and calibrated. It has to be noted that the agreement observed here does not account for additional variability in output data that could result from the differences in the potentially subjective assumptions made by different SP2 users in the data processing.

\section{Motivation}

Soot particles are emitted into the atmosphere during incomplete combustion. They contain, depending on the source, variable amounts of black carbon (BC; sometimes also referred to as EC (elemental carbon) when measured with thermal methods), organic carbon (OC), inorganic salts, and trace elements. BC is of particular interest as it is the most significant aerosol that directly affects the climate by strongly absorbing solar and infra-red radiation in the atmosphere (Bond et al., 2007; Shindell et al., 2012). With time, BC can gain additional coatings through the condensation of low volatile compounds, through coagulation processes, or through cloud processing. This ageing affects the optical, cloud condensation nuclei, and ice nuclei properties of BC containing particles, as well as their lifetime (Schnaiter et al., 2005; McFiggans et al., 2006; Koch et al., 2011; Crawford et al., 2011). It is therefore important to accurately measure $\mathrm{BC}$ mass concentration and mixing state to understand and model its climate impact.

Unfortunately, exact measurement of $\mathrm{BC}$ remains difficult, although consistent results can be achieved with different methods (Slowik et al., 2007; Kondo et al., 2011). The Single Particle Soot Photometer (SP2; Stephens et al., 2003) can contribute to addressing the need for $\mathrm{BC}$ characterisation by directly measuring the mass of refractory black carbon (rBC; hereafter referred to as BC) in individual particles. This observation can provide the mass and number size distributions of BC cores in the SP2's size range. Additionally, the SP2 provides optical sizing of particles. A secondary data product of the SP2 is a semi-quantitative measure of the coating thickness of non-refractory material on individual $\mathrm{BC}$ cores.
Several studies have previously characterized the detection efficiency of the SP2 (Schwarz et al., 2010), the coating effect on the mass measurement (Moteki and Kondo, 2007; Slowik et al., 2007; Cross et al., 2011), the consistency of the mass measurement compared to other methods to measure BC (Slowik et al., 2007; Kondo et al., 2011; Cross et al., 2011), and the influence of calibration materials on the mass measurement (Moteki and Kondo, 2010; Laborde et al., 2012). In addition, several methods have been used to treat the scattering signal in order to calculate the coating thickness of the particles (Gao et al., 2007; Moteki and Kondo, 2008; Schwarz et al., 2008). However, the reproducibility and the accuracy of these data products delivered by the SP2 have only been partly characterised.

We present here results from the SOOT11 campaign (performed at the AIDA chamber, Karlsruhe) that aimed at comparing 6 SP2s from 6 different institutes in order to comprehensively assess the reproducibility and the accuracy of most of the data products that can presently be calculated from SP2 measurements.

\section{Experimental methods}

\subsection{Single Particle Soot Photometer (SP2)}

\subsubsection{Description}

The SP2 instrument is available commercially (Droplet Measurement Technology, Boulder, USA). Its operating principle has been described previously (e.g. Stephens et al., 2003; Schwarz et al., 2006; Moteki and Kondo, 2007). Briefly, the particles in an aerosol sample are aerodynamically directed into the centre of a Gaussian shaped laser beam (Nd:YAG; $\lambda=1064 \mathrm{~nm}$ ) with $100 \%$ collection efficiency (within a certain range defined in Sect. 4.1.3). The particle beam width is $\sim 1 / 4$ of the laser beam width. The particles containing a BC core absorb the laser light, thereby heating up and loosing their non-refractory coatings. Eventually, the $\mathrm{BC}$ cores reach their vaporization temperature, and incandesce. The SP2 quantifies the refractory black carbon mass in each of these particles indirectly by measuring the peak intensity of the thermal emission from the $\mathrm{BC}$ core at its boiling point. The visible thermal radiation is captured, in the SP2s considered here, by two photomultiplier tubes (PMTs; Hamamatsu Inc., Japan, model H6779) equipped with optical bandpass filters. By default, the broader bandpass lets light through in between $350 \mathrm{~nm}$ and $800 \mathrm{~nm}$ (Schott KG5 filter) and the narrower one in between $630 \mathrm{~nm}$ and $800 \mathrm{~nm}$ (Schott KG5 and RG630 filters). Note that the PMT's detection efficiency as a function of the wavelength falls precipitously after $650 \mathrm{~nm}$ and restricts the amount of light detected, therefore several research groups have modified the configuration of this second channel. Only unmodified instruments were 
used in this study to compare the performance of different SP2 instruments.

The SP2 detects the light elastically scattered by the particles using an avalanche photo diode (APD) in order to determine the optical size of the particles. Additionally, a twoelement APD (TEAPD; Gao et al., 2007) is used to determine the particle's position in the laser beam. This is required for reliable optical sizing of BC-containing particles, which evaporate as they cross the laser beam. Comparing the optical size with $\mathrm{BC}$ mass provides information on the mixing state of BC. A detailed description of the data analysis assumptions and methodology can be found in Sect. 3.

\subsubsection{SP2 version of involved institutes}

Six SP2s from six different research groups took part in the intercomparison. The following acronyms will be used to designate the respective SP2s:

- DLR: Deutsches Zentrum für Luft- und Raumfahrt

- KIT: Karlsruhe Institute of Technology

- LGGE: Laboratoire de Glaciologie et Géophysique de l'Environnement

- MPI: Max Planck Institute for Chemistry

- PSI: Paul Scherrer Institute

- UMN: The University of Manchester.

This study covers a range of different SP2 revisions. The most relevant specifications of all the compared SP2s are provided in Table 1. In all SP2s, the detector signals are amplified with two gains, hereafter referred as high- and low-gain. Both amplification gains can be varied while the high-to-low ratio remains constant. Adjusting the amplification gain influences the detection range of the SP2 in terms of BC mass per particle.

In the earlier versions of the SP2 (A-C), only the highgain signals are acquired, while in the newer version $\mathrm{C}^{*}$, both low-gain and high-gain channels are acquired. Within the SP2 community, all the instruments use the same combination of optical filters and PMT for the broadband channel, while different approaches are used for the narrowband channel (see Sect. 2.1.1). The broadband channel is therefore used here for the comparison of the BC measurements by all SP2s. The high-gain output is used for the comparison of all the SP2s apart from LGGE's SP2, which is the only version $\mathrm{C}^{*}$ instrument used here. The low-gain output was used for the latter SP2 due to its better overlap in detection range with the other SP2s.

\subsubsection{Recommended SP2 adjustments}

The following list contains the main adjustments and calibration steps that are required, in our opinion, to achieve optimum performance of an SP2:
- Laser alignment: the laser's output coupler position should be checked, following the manufacturer's instructions (SP2 operator manual, Droplet Measurement Technologies, 2012), and aligned to achieve a laser beam in TEM00 mode, which implies a Gaussian radial intensity distribution.

- Mode aperture alignment: the mode aperture (used to constrain the spatial mode of the laser) should be aligned (SP2 operator manual, 2012) such that a TEM00 mode is obtained without attenuating the laser beam.

- Detector block horizontal alignment: the detector block, also holding the nozzle creating the particle beam, should be aligned horizontally, following the manufacturer's instructions (SP2 operator manual, 2012), such that the particle beam crosses the centre of the laser beam. This adjustment should be performed using nonabsorbing spherical particles such as polystyrene latex spheres (PSL).

- Scattering detector alignment: the position of the APD should be adjusted (by moving the detector board in and out) to a position near to the focal plane of the optical lens in order to almost maximize the scattering signal amplitude. Note that the maximum should not, however, be reached in order to avoid local saturation of the APD for larger particles.

- Two-element APD detector alignment: the vertical position of the TEAPD should be adjusted such that the split point (the point where the signal crosses the baseline) is detectable for pure BC particles with a mass of $\sim 6.7 \mathrm{fg}$. In addition, the TEAPD should be adjusted (as for the scattering detector) such that the signal amplitude is almost maximized.

- Laser power adjustment: the intracavity laser power should be adjusted (by varying the power of the pump laser) until the color ratio (defined as the ratio between broadband and narrowband incandescence peak height) becomes independent of laser power. The procedure described in Schwarz et al. (2010) with a polydisperse pure BC sample such as fullerene soot should be used. This procedure guarantees that the calibration of the incandescence detector is independent of laser power. It is also necessary for maximal detection efficiency of the small BC particles as they might not reach their boiling point otherwise. However, this condition is not sufficient for unit detection efficiency of small BC particles, as they can remain undetected for other reasons (see Sect. 4.1.3).

- Flow measurement: the inlet flow of each instrument should be checked to assure correct calibration of the SP2's internal flow measurement (differential pressure gauge). 
Table 1. SP2 specifications.

\begin{tabular}{lcc}
\hline Institute & Revision & Acquisition card type \\
\hline $\begin{array}{l}\text { Deutsches Zentrum für Luft- und Raumfahrt (DLR) } \\
\text { Karlsruhe Institute of Technology (KIT) }\end{array}$ & B & 12 bits $-5 \mathrm{MHz}-4$ channels \\
$\begin{array}{l}\text { Laboratoire de Glaciologie (LGGE) } \\
\text { et Géophysique de l'Environnement }\end{array}$ & C & 12 bits $-5 \mathrm{MHz}-4$ channels \\
Max Planck Institute for Chemistry (MPI) & & 14 bits $^{\mathrm{a}}-2.5 \mathrm{MHz}-8$ channels \\
Paul Scherrer Institute (PSI) & C & 12 bits $-5 \mathrm{MHz}-4$ channels \\
The University of Manchester (UMN) & B & 12 bits $-5 \mathrm{MHz}-4$ channels \\
\hline
\end{tabular}

a Labelled as 16 bits but 14 bits resolution in reality.

- Calibration: the incandescence detectors should be calibrated using fullerene soot and/or Aquadag (Baumgardner et al., 2012). The scattering detector should be calibrated using non-refractory spherical particles of a certified size such as PSL size standards. More details on the calibration materials and procedures can be found in Sect. 2.2.

Most of the above adjustment and calibration steps were applied to all the SP2s in this study. It has to be noted that the KIT's SP2 mode aperture was misaligned during part of the campaign (before 29 November 2010), resulting in a laser power lower than required for stable incandescence calibration and optimal counting efficiency at the lower detection limit.

The sample flow rates were measured using a bubble flow meter and were $0.12 \mathrm{~L} \mathrm{~min}^{-1}$ for all SP2s, except for the MPI instrument with $0.08 \mathrm{~L} \mathrm{~min}^{-1}$. The sheath air flow rate was set to $1 \mathrm{~L} \mathrm{~min}^{-1}$ for all SP2s.

\subsection{The SOOT11 campaign}

The SP2's response to different types of aerosol was tested during the SOOT11 campaign, lasting for 3 weeks, at the AIDA facility using the following experimental setup and aerosol samples.

\subsubsection{AIDA chamber and sampling manifold}

The large aerosol and cloud simulation facility AIDA (Aerosols Interaction and Dynamics in the Atmosphere) in Karlsruhe, described in more details elsewhere (Wagner et al., 2009), is a tool for investigating physical and chemical aerosol processes. The AIDA facility comprises a $84.5 \mathrm{~m}^{3}$ aluminium chamber that can be operated at variable pressure, temperature, and humidity conditions.

The AIDA facility is equipped with an extensive suite of state of the art instruments. During the SOOT11 campaign, the AIDA chamber was used as a reservoir into which particles were introduced and from where samples were taken. Additionally, the AIDA was used to simulate ageing processes such as coagulation and condensation of secondary organic aerosol (SOA).
Filter samples were taken in order to determine the particle's total carbon (TC), elemental carbon (EC) and organic carbon (OC) content, offline, using a Sunset analyzer (Birch and Cary, 1996). The NIOSH 5040 protocol, defining the sample preparation protocol, the temperature set points, the residence times at each temperature step, and the gas to be used, was applied. The transmitted laser light was used for the charring correction. Particle number size distributions were measured using a scanning mobility particle sizer (SMPS). Light absorption by the particles was measured using photoacoustic spectrometry (PAS). The PAS instrument used in this study is described in detail elsewhere (Schmid et al., 2006). Briefly, it uses a power-modulated, frequencydoubled Nd:YAG laser $(\lambda=532 \mathrm{~nm})$, in an optical resonator equipped with a microphone, for a direct airborne measurement of the aerosol absorption coefficient. This method is unaffected by light scattering from the filter matrix and the collected aerosol as would occur with a filter-based measurement.

The experimental setup of this study is shown in Fig. 1. A common $6 \mathrm{~mm}$ stainless steel sampling line was connected to the AIDA chamber through which six SP2s and a condensation particle counter (CPC) sampled. The sample concentration was adjusted using one or two dilution stages (PALAS VKL-10; 1:10 dilution each), when necessary, to avoid coincident particles in the SP2's laser beam.

The common SP2/CPC sampling line was sometimes disconnected from the AIDA chamber and connected to the calibration system (details in Sect. 2.2.2) and ambient air (details in Sect. 2.2.6).

\subsubsection{Calibration aerosols}

Aqueous suspensions of fullerene soot (Alfa Aesar; stock 40971, lot FS12S011) and Aquadag (Aqueous Deflocculated Acheson Graphite from Acheson Inc., USA) samples were used to calibrate the sensitivity of the SP2's broadband incandescence detector to $\mathrm{BC}$ mass. The nebulized particles were neutralized using a ${ }^{85} \mathrm{Kr}$ source and selected by their mobility diameter using a differential mobility analyser (DMA) before entering the common sampling line. The effective density and stability of these Aquadag and fullerene soot samples 


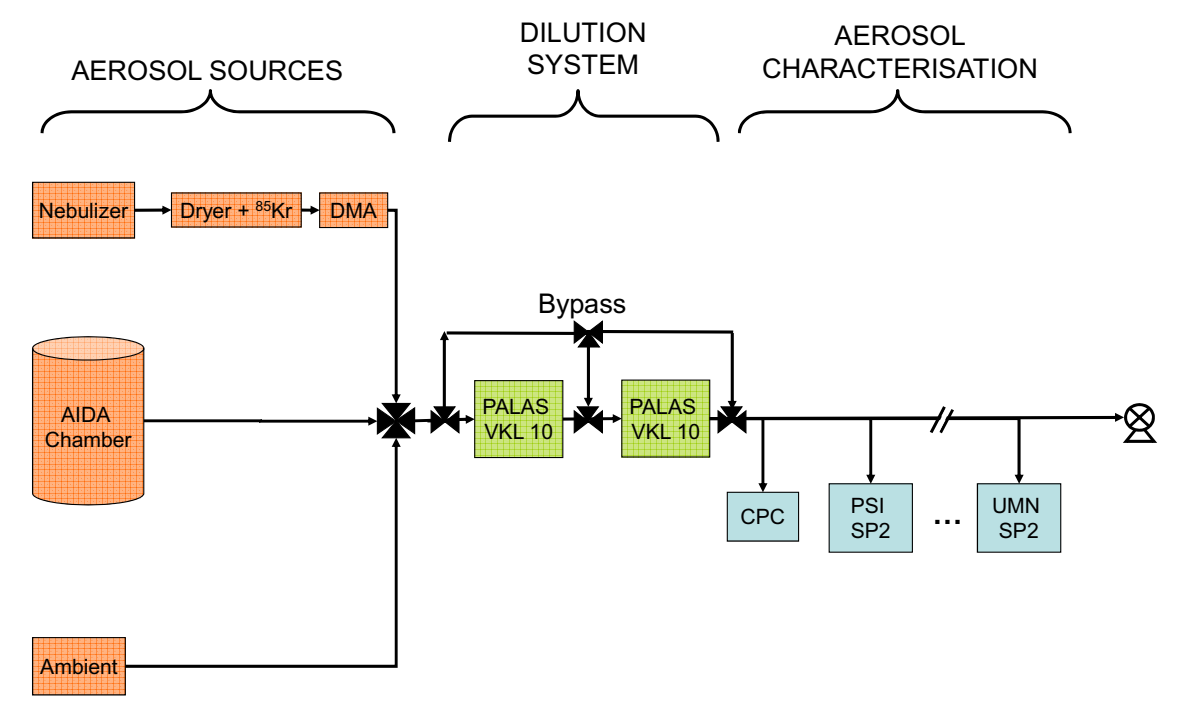

Fig. 1. Experimental setup used during the SOOT11 campaign.

was previously characterized by Gysel et al. (2011), allowing for the particle mass to be calculated from the mobility diameter. The CPC measured in parallel in order to determine the mass-resolved counting efficiency of the SP2 (see Sect. 4.1.3).

The same setup was also used to calibrate the scattering detector with 150, 220, 269, 350 and $600 \mathrm{~nm}$ diameter PSL size standard particles (Thermo Scientific, formerly Duke Scientific). Only the results using the $269 \mathrm{~nm}$ PSL particles ( $220 \mathrm{~nm}$ for the LGGE's SP2) will be presented here as the calibrations using the other sizes are similar.

\subsubsection{Secondary organic aerosol production}

Secondary organic aerosol (SOA) was produced by ozonolysis of $\alpha$-pinene. $\alpha$-pinene and ozone were sometimes introduced into the empty AIDA chamber, resulting in the formation of a polydisperse SOA aerosol consisting of spherical purely scattering particles. At other times $\alpha$-pinene and ozone were introduced into the chamber previously filled with soot particles resulting in condensation of the SOA onto the $\mathrm{BC}$ particles, thereby increasing the coating thickness. Typical $\alpha$-pinene and ozone concentrations ranged between 8-98 ppb and 230-340 ppb, respectively. Details about the generation of SOA and the coating of soot in the AIDA chamber can be found elsewhere (Saathoff et al., 2003, 2009).

\subsubsection{CAST soot}

Combustion aerosol standard (CAST soot) was produced using a mini-CAST propane burner (Jing-CAST Technologies). Particles with various OC/EC ratios were investigated by varying the burning conditions ( $\mathrm{C} / \mathrm{O}$ ratio). We will, however, only report here the results of the experiment using
CAST soot with an $\mathrm{C} / \mathrm{O}$ setting of 0.29 corresponding to a measured OC to TC ratio of $\sim 60 \%$ (Sect. 4.5 ).

\subsubsection{Diesel car exhaust}

A diesel engine test bench, holding a EURO-5 with a $2.0 \mathrm{~L}$ series Volkswagen diesel engine (http://www.motor-talk.de/ forum/aktion/Attachment.html?attachmentId=714834) with bypassed diesel particle filter, was used to produce diesel exhaust particles. The engine was operated with standard diesel fuel at 2000 revolutions/min and a torque of 81 and $195 \mathrm{Nm}$. Water vapour, volatile hydrocarbons, and $\mathrm{NO}_{\mathrm{x}}$ were removed from the diesel exhaust by a series of denuders (Saathoff et al., 2003) before injecting it into the AIDA chamber.

\subsubsection{Ambient sample}

The SP2 is typically used to measure outdoor aerosol. It is therefore important to compare the SP2's response and agreement using outdoor samples. An extension to the sampling line was setup in order to sample outdoor air from the top of the roof.

\section{Data analysis procedures}

\subsection{Data analysis software}

Due to the high amount of single particle data produced by the SP2, the data analysis requires automated data processing. Several options are available throughout the SP2 community, including user-developed procedures and manufacturer-provided procedures (PAPI). Two institutes with such user-developed procedures were present (PSI and UMN) during the SOOT11 campaign, allowing for a comparison. Both sets of procedures were found to produce similar 
calibration curves as well as BC mass and number size distributions from the same set of raw data (see Supplement, Fig. S1). PSI's toolkit was used to analyse all data from the intercomparison as the lead author is familiar with this one and as it also provides more advanced data products. The statistical parameters obtained in this study (Table 2) therefore reflect only the difference between instruments, and it has to be noted that additional variability in output data from other studies could result from the differences in the potentially subjective assumptions made by different SP2 users in the data processing.

\subsection{BC mass determination}

The BC mass in single particles is indirectly determined by measuring the intensity (peak height) of the light emitted at the incandescence of $\mathrm{BC}$ particles, as previously mentioned. However, an empirical calibration is needed to link the measured incandescence signal to the BC mass. Aquadag and fullerene soot are two common calibration materials that have good stability and cover particle mass ranges appropriate for the SP2. The SP2's sensitivity to fullerene soot has been found to be the closest to that of ambient and diesel BC (Moteki and Kondo, 2010; Laborde et al., 2012). The fullerene soot calibration was therefore applied to determine BC mass for all data presented in this study, unless stated otherwise. The mass of the fullerene soot and Aquadag calibration particles was inferred from the selected mobility diameter using the effective density values provided in Gysel et al. (2011). The data from the CAST soot experiment was also treated using the fullerene soot calibration, due to lack of better knowledge on the SP2's sensitivity to BC from the CAST burner. The Aquadag calibration curves will be used in Sect. 5 to discuss the influence of calibration curve choice on the measured BC mass.

Number and mass size distributions of BC cores are commonly shown as a function of $\mathrm{BC}$ core mass equivalent diameter, $D_{\mathrm{MEV}}$, which is calculated from the particle mass assuming a void-free BC material density of $1800 \mathrm{~kg} \mathrm{~m}^{-3}$ (Moteki and Kondo, 2010).

\subsection{Optical diameter and coating thickness determination}

The differential scattering cross section and optical diameter of single particles is determined by measuring the intensity of the laser light elastically scattered by the particles into the solid angle covered by the detector (cone with a full opening angle of $60^{\circ}$ collecting light between $15^{\circ}-75^{\circ}$ and $105^{\circ}-$ $165^{\circ}$; Gao et al., 2007). Absolute calibration of the scattering measurement, i.e. the factor between the calculated differential scattering cross section of a particle and the corresponding measured scattering signal amplitude, was done using PSL sphere size standards with a diameter of $269 \mathrm{~nm}$ ( $220 \mathrm{~nm}$ for the LGGE's instrument). The term differential denotes the fact that the scattering detector measures the scattered light only in a certain solid angle, corresponding to a portion of the total scattered light. For conciseness, we will hereafter refer to the differential scattering cross section simply as the scattering cross section.

The scattering cross section of the PSL sphere was calculated using Mie theory for spherical particles (Bohren and Huffman, 1983) with a refractive index (RI) of $n=1.59+0 i$, and using the known SP2 solid angle. A single size calibration of the scattering detector is sufficient as the ratio between scattering cross section and scattering signal amplitude is independent of particle size. The validity of this assumption was confirmed for all SP2s by measuring several PSL sizes.

Non-absorbing, purely scattering particles will cross the laser beam unaltered, and thus the scattering cross section corresponding to the maximum scattering peak height observed at the centre of the laser beam represents the whole particle. The optical diameter of the particle is then obtained by comparing the calibrated scattering cross section measurement with the calculated size dependence of the scattering cross section of spherical particles with a certain refractive index. The choice made for the refractive index in the case of non-absorbing SOA particles will be discussed in Sect. 4.4. The measured scattering amplitude is proportional to the intensity of the laser beam, which is assumed to be constant between scattering detector calibrations (four in total) for the analysis in this paper. Shortcomings of this assumption will be discussed in Sect. 4.1.2.

The particles containing a BC core absorb the laser light, thereby heating up and loosing their non-refractory coatings. The size and scattering cross section of $\mathrm{BC}$-containing particles decrease as they cross the laser beam, first due to evaporation of non-refractory coatings followed by evaporation of the $\mathrm{BC}$ core. The scattering cross section and size of the whole particle can therefore be determined from the leading edge only (LEO) of the scattering signal recorded very early in the laser beam. However, this requires a correction accounting for the non-uniform nature of the laser intensity as a function of position in the beam. Two alternative methods have previously been described to determine the scattering cross section of BC containing particles (Gao et al., 2007; Moteki and Kondo, 2008). In this study we apply the LEO-fit method by Gao et al. (2007), which uses the particle's position in the laser beam (inferred from the signal of the TEAPD combined with information about the average speed of the particles across the laser) to determine the scattering cross section of BC containing particles. The step from scattering cross section to particle diameter is also more complex, as $\mathrm{BC}$ particles from different sources might have different RI and are often non-spherical. In order to estimate the optical diameter, we compare the calibrated scattering cross section measurement with Mie calculations for spherical two component particles with a concentric core-shell morphology as in Schwarz et al. (2008). The core size is held fixed at the 
Table 2. Summary of the SP2 repeatability obtained during this study, for different parameters. "Repeatability" refers to the range between minimum and maximum values observed by 6 SP2 instruments for a certain quantity.

\begin{tabular}{lcl}
\hline Parameter description & $\begin{array}{c}\text { Repeatability } \\
(\% \text { of the average })\end{array}$ & Applicable range \\
\hline Number size distribution & $\pm 5 \%$ & BC core mass $\geqslant 1 \mathrm{fg}\left(D_{\mathrm{MEV}} \approx 100 \mathrm{~nm}\right)$ \\
Mass size distribution & $\pm 10 \%$ & BC core mass $\geqslant 1 \mathrm{fg}\left(D_{\mathrm{MEV}} \approx 100 \mathrm{~nm}\right)$ \\
$\begin{array}{l}\text { Optical number size distribution } \\
\text { for purely scattering particles }\end{array}$ & $\pm 15 \%$ & $D_{\mathrm{Opt}} \geqslant 140 \mathrm{~nm}$ \\
Coating thickness & $\pm 17 \%$ & $150 \mathrm{~nm} \leqslant D_{\mathrm{MEV}} \leqslant 400 \mathrm{~nm}$ \\
\hline
\end{tabular}

mass equivalent diameter of the $\mathrm{BC}$ core, corresponding to the BC mass determined by the incandescence measurement, while the overall particle diameter is varied until the calculated scattering cross section matches the measurement. The coating thickness is then calculated as the difference between the radii of the total particle and the $\mathrm{BC}$ core.

However, the LEO-fit method only provides accurate results if it is performed before the coating starts evaporating. To ensure this is the case, the LEO-fit was performed up to $2 \mu$ s before the earliest incandescence observed for the entire sample (equivalent to a scattering signal amplitude ranging from 2 to $8 \%$ of the maximum amplitude, for the different SP2s). Careful tests with more restrictive LEO-fit limits have been done to ensure that the above choice of LEO-fit limits is appropriate for all SP2s.

The coating thickness provided by the core-shell Mie model is only accurate if the RIs assumed for the BC core and the non-refractory matter are, and to the extent that Mie theory is able to replicate the scattering behaviour for the complex particle morphology, under study. For this study, the $\mathrm{RI}$ of the $\mathrm{BC}$ core was chosen such that the optical diameter of the bare $\mathrm{BC}$ core (just determined before incandescence) agreed with the $\mathrm{BC}$ core mass equivalent diameter as calculated from the incandescence signal. Consistency between $\mathrm{BC}$ mass measurement and optical sizing of the BC core was achieved for the CAST soot by using an RI of $n=1.9+0.8 i$. This value is within the likely RI range of light absorbing carbon reported by Bond and Bergstrom (2006). Using an RI of $n=2.26+1.26 i$ resulted in consistent results for the ambient $\mathrm{BC}$ particles, which is in agreement with literature for ambient BC (Moteki et al., 2010). In both cases, an RI of $n=1.5$ was used for the coating matter. This RI (at the SP2's wavelength) has previously been used for similar coating thickness analyses of ambient particles (Schwarz et al., 2008), and it is also representative of aliphatic hydrocarbons and polycyclic aromatic hydrocarbons (PAHs; Sutherland et al., 1994), which are major components of the OC in fresh CAST soot (Slowik et al., 2007). The composition of the organic coatings of CAST soot changes during the addition of SOA coatings. The quantitative comparison between the coating thickness measurement and the independent OC volume fraction measurement by the Sunset in- strument (Sect. 4.5 and Table 5) is done for fresh CAST soot. Therefore, we use the RI representing the OC coating of fresh CAST soot for the coating thickness analysis of this experiment.

\section{Results}

\subsection{Calibration: stability and detection limit}

\subsubsection{BC mass calibration}

Accurate BC mass concentration measurements are only possible if calibrations of the incandescence detector are reproducible. For this reason we compare in Fig. 2 the results from two fullerene soot calibrations performed on 16 November 2010 and 1 December 2010. Size-selected fullerene soot particles with mass between $0.2 \mathrm{fg}\left(D_{\mathrm{MEV}}=60 \mathrm{~nm}\right)$ and $60 \mathrm{fg}$ $\left(D_{\mathrm{MEV}}=352 \mathrm{~nm}\right)$ were fed into the common sampling manifold for this purpose (Sect. 2.2). The comparison of the calibration curves highlights the wide range of sensitivities within the available SP2s, resulting from different signal amplification gains. The sensitivity to an $8.9 \mathrm{fg}$ fullerene soot particle indeed varies by a factor of $\sim 3.5$ (from $2.6 \mathrm{~V}$ to 9.3 V; Table 3), excluding LGGE's SP2. This difference in gain causes the $\mathrm{A} / \mathrm{D}$ converter to saturate at different $\mathrm{BC}$ masses ranging from $18 \mathrm{fg}$ to $74 \mathrm{fg} \mathrm{BC}$. This result is consistent with a previous study where differences were found in the calibration slope (Cross et al., 2011). Particles with $\mathrm{BC}$ mass above saturation are still detected, but their BC mass cannot be quantified. Note that the LGGE SP2 has a higher A/D converter resolution. It can therefore be operated at a lower gain, resulting in a higher upper detection limit while retaining the lower detection limit. The differences in gain can potentially influence the lower detection limit for BC mass too and will be discussed in Sect. 4.1.3.

A maximum drift of up to $9 \%$, in the range $0.2 \mathrm{fg}-60 \mathrm{fg}$ was observed between the two calibrations for individual instruments (Fig. 2, shaded area). This includes the drift of the entire setup, i.e. the variability of calibration material, DMA and SP2. The accuracy of the BC mass determination is directly affected by the calibration reproducibility and cannot therefore be expected to be better than $9 \%$ for this setup. 


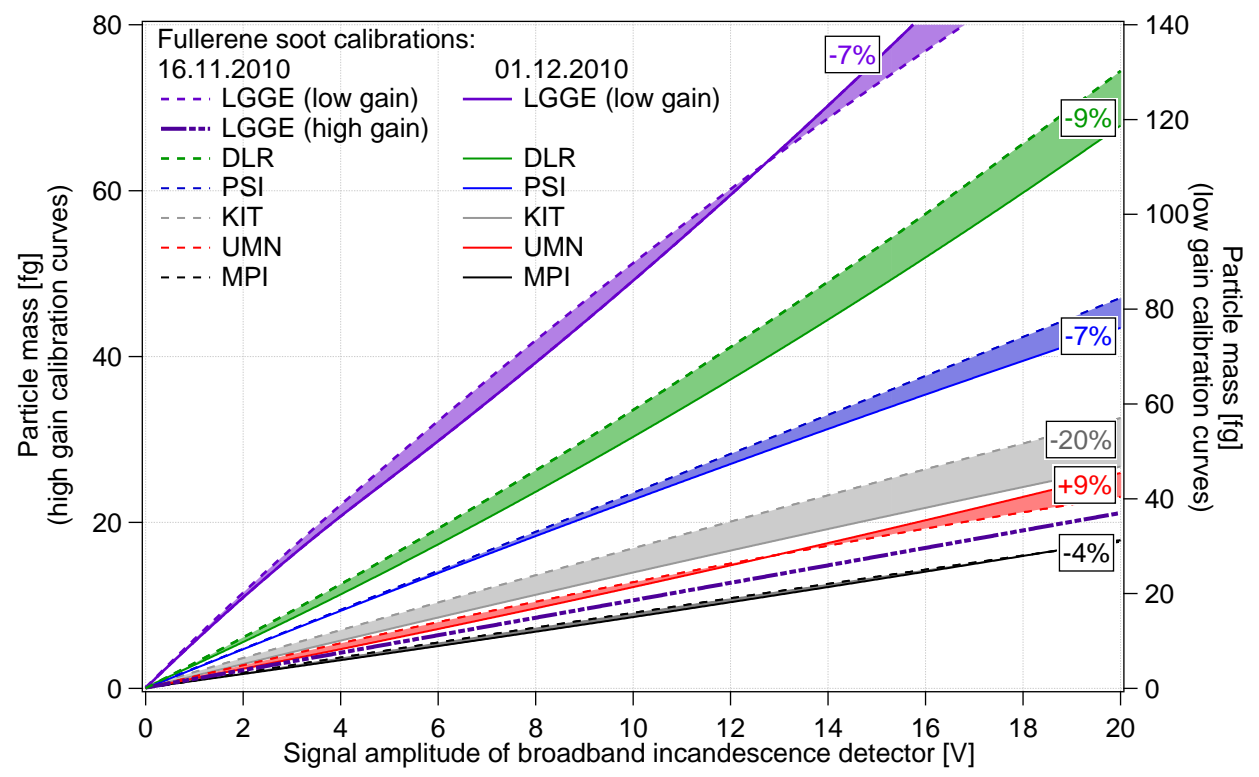

Fig. 2. Comparison of the fullerene soot calibrations of the broadband incandescence detector performed for all the SP2s on 16 November 2010 (dashed lines) and 1 December 2010 (solid lines). The shadings indicate the drift between these two calibrations, while the numbers in the boxes indicate the maximal difference in the $0.2-60 \mathrm{fg} \mathrm{BC}$ range. This reflects the drift of the entire setup, including the variability of calibration material, DMA and SP2s. Calibration curves are shown for the high-gain output of the broadband incandescence channel of all SP2s and additionally for the low-gain output of LGGE's SP2.

Table 3. Aquadag (AQ) and fullerene soot (FS) calibration results for all SP2s (see also Fig. 2) for the broadband incandescence (BB) channel. The fullerene soot calibration reported was performed on 16 November 2010 (dashed lines in Fig. 2). The calibration drift represents the biggest ratio between this calibration and that performed on 24 November 2010. The Aquadag calibration reported here was performed on 24 November 2010. The Aquadag to fullerene soot ratio was calculated using the calibrations both performed on 24 November 2010.

\begin{tabular}{lrrrrr}
\hline SP2 & $\begin{array}{r}\text { Mass at saturation } \\
\text { (FS cal.) }[\mathrm{fg}]\end{array}$ & $\begin{array}{r}\text { BB cal. drift } \\
\text { (FS cal.) }\end{array} \%$ & $\begin{array}{r}\text { BB volt. [V], } \\
\text { FS, 8.9 fg }\end{array}$ & $\begin{array}{r}\text { BB volt. [V], } \\
\text { AQ, 8.9 fg }\end{array}$ & $\begin{array}{r}\text { AQ to FS signal } \\
\text { ratio at 8.9 fg }\end{array}$ \\
\hline DLR & 74 & +9 & 2.9 & 3.9 & 1.37 \\
MPI & 18 & +4 & 9.8 & 12.4 & 1.26 \\
PSI & 47 & +7 & 3.7 & 4.8 & 1.28 \\
KIT & 33 & $+20^{\mathrm{b}}$ & 5.2 & 7 & 1.35 \\
UMN & 23 & -9 & 6.8 & 9.6 & 1.42 \\
LGGE & 205 & -7 & 0.9 & 1.2 & 1.32 \\
\hline
\end{tabular}

a Maximal difference in the mass range $0.2-60 \mathrm{fg}$ BC. This drift includes potential drifts of the SP2 and the DMA, as well as small variability of the fullerene soot's effective density. ${ }^{b}$ This larger drift is due a strong increase of laser power between the two calibrations from an insufficient level to a sufficient level.

The $\mathrm{BC}$ calibration is independent of the laser power only if the laser power is sufficiently high. The KIT SP2's laser power increased from an insufficient level to a sufficiently high level in between the two calibrations, as a result of the mode aperture alignment. This caused a higher calibration drift of $20 \%$, which is not representative of typical SP2 calibration stability.

\subsubsection{Scattering detector calibration}

The scattering measurement of the SP2 can be used to infer the absolute intracavity laser intensity (Schwarz et al., 2010), but its main purpose is to determine the optical size of the particles. Accurate optical sizing can only be achieved if the scattering measurement is calibrated (Sect. 3.3) and if the calibration factor obtained is stable for a steady SP2 configuration (i.e. over a measurement campaign or between two calibrations). The scattering calibration factor is defined as the ratio between the scattering amplitude measured for PSL size standards and the scattering cross section calculated using Mie theory. The temperature dependence of the APD's sensitivity (Schwarz et al., 2010) can be a potential source of calibration drift, though this effect should not have influenced our calibration measurements as all of them were performed within $\pm 2{ }^{\circ} \mathrm{C}$ for a certain instrument (Fig. 3a). The 
scattering signal is also proportional to the laser intensity. Changes of the relevant laser intensity, i.e. the peak intensity seen by the particles crossing the laser beam, are thus a major reason for drifts of the scattering calibration factor. This is in contrast to the incandescence detector calibration, which is independent of laser power. The most common causes for drifts of the relevant laser intensity are degrading integrated intensity of the laser beam due to a contamination of the laser optics, changing laser beam shape due to shifting of laser optic alignment, or changes of the position where the particles cross the laser beam, exposing the particles to a less intense part of the laser beam.

An independent measure of the intracavity laser power is required in order to determine how much the drift of the integrated laser power can account for the scattering calibration drift. The SP2's YAG power monitor reading provides a measure of the intracavity laser power by monitoring the light leakage through the high reflectivity output coupler mirror of the laser cavity. However, the ratio between intracavity laser power and YAG power monitor reading is temperature dependent (Schwarz et al., 2010) and the laser power can only be reliably estimated from this measurement by following the temporal evolution of the YAG power monitor at a fixed temperature (see Supplement, Fig. S2). The temperature corrected YAG power monitor readings, obtained by interpolating readings taken at a fixed temperature, are shown in Fig. $3 \mathrm{~b}$ for all scattering detector calibrations. The integrated laser power was almost stable for the SP2s from MPI, UMN, LGGE and PSI, with drifts of $6.3 \%, 0.8 \%, 1.6 \%$ and $4.3 \%$, respectively. KIT's SP2 laser power increased dramatically after the mode aperture realignment (done on 29 November 2010). DLR's SP2 laser power gradually dropped (with a drift of $27 \%$ ) between 17 and 24 November, probably due to abnormally shifting laser optics, causing a partial attenuation of the laser by the mode aperture (see also Supplement, Fig. S2). DLR's SP2 laser power recovered and became stable (no drift observed) after the realignment of the output coupler on 26 November.

During this study, scattering calibrations were performed 4 times. The sensitivity of the scattering measurement differed by a factor of $\sim 3$ between the SP2s (Table 4). Figure 3c shows the measured scattering signal amplitudes for $269 \mathrm{~nm}$ PSL particles (220 nm for LGGE's SP2) of all calibrations normalized by that of the first calibration. This normalisation was done in order to identify calibration drifts. Figure $3 \mathrm{~d}$ shows the ratio of the measured scattering signal amplitude to the temperature corrected YAG power monitor reading for all calibrations, again relative to that of the first day. The division by laser power was done to determine the contribution of changing integrated laser power to the observed calibration drifts.

It can be seen that the KIT SP2 shows a major scattering signal increase between the second and the third calibrations (Fig. 3c), for the most part caused by the increase of integrated laser power (Fig. 3b). This is confirmed by the fact
Table 4. High-gain scattering channel calibration results for all SP2s (see also Fig. 3) using $269 \mathrm{~nm}$ (220 nm for LGGE) PSL particles. The calibration performed on 17 November 2010 for most of the instruments and in addition that performed on 30 November 2010 are reported for those instruments that experienced a laser power drift.

\begin{tabular}{lc}
\hline $\begin{array}{l}\text { SP2 } \\
\text { calibration date }\end{array}$ & $\begin{array}{c}\text { Scattering signal }[\mathrm{V}]^{\mathrm{a}} \\
\text { for PSL spheres }\end{array}$ \\
\hline KIT 17 November 2010 & $3.5^{\mathrm{b}}$ \\
KIT 30 November 2010 & $10.1^{\mathrm{b}}$ \\
MPI 17 November 2010 & 3.8 \\
UMN 17 November 2010 & 4 \\
PSI 17 November 2010 & 5.8 \\
PSI 30 November 2010 & 5.1 \\
DLR 17 November 2010 & 7.8 \\
DLR 30 November 2010 & 6 \\
LGGE 30 November 2010 & 11.8 \\
\hline a For a PSL of a diameter of 269 nm or 220 nm for LGGE. ${ }^{\mathrm{b}}$ This \\
larger difference is due a strong increase of laser power between the \\
two calibrations from an insufficient level to a sufficient level.
\end{tabular}

that the laser power corrected calibrations after the power increase differ by less than $20 \%$ from those before (Fig. 3d).

For the UMN SP2, the difference between the highest scattering signal and the lowest is around $20 \%$ both with and without dividing by laser power (Fig. 3c and d). This indicates that the integrated laser power is not responsible for this drift and that a $20 \%$ calibration drift in 3 weeks is therefore possible even at stable integrated laser power.

In a similar way, the MPI SP2 shows only a very small integrated laser power drift. Its scattering signal shows a $20 \%$ drift without laser power correction (Fig. 3c), reducing to $10 \%$ after dividing by the laser power (Fig. 3d).

The PSI's SP2 shows a scattering signal drift of $30 \%$ that is hardly reduced by dividing by the laser power. This larger drift compared to other instruments can likely be explained by a movement of the laser position. The SP2's optics were cleaned shortly before the campaign and the YAG crystal was likely not totally settled. The position of the laser beam maximum shifts when the YAG crystal or the output coupler moves a little. The laser power can remain stable as long as the mode aperture does not attenuate it. However, the particles will not hit the centre of the laser beam anymore, resulting in a lower scattering signal (Fig. 3c-d) despite almost stable integrated laser power (Fig. 3b). This interpretation is consistent with a degrading detection efficiency for small BC cores, as discussed in Sect. 4.1.3.

The scattering signal of the DLR SP2 shows a $25 \%$ drift (Fig. 3c) that decreases to $15 \%$ after dividing by the laser power (Fig. 3d). The DLR SP2 output coupler was realigned between the second and the third calibration, increasing the integrated laser power (Fig. 3b). However, the detector block was not realigned. Consequently, the particle beam did not anymore cross the centre of the laser beam, thereby 


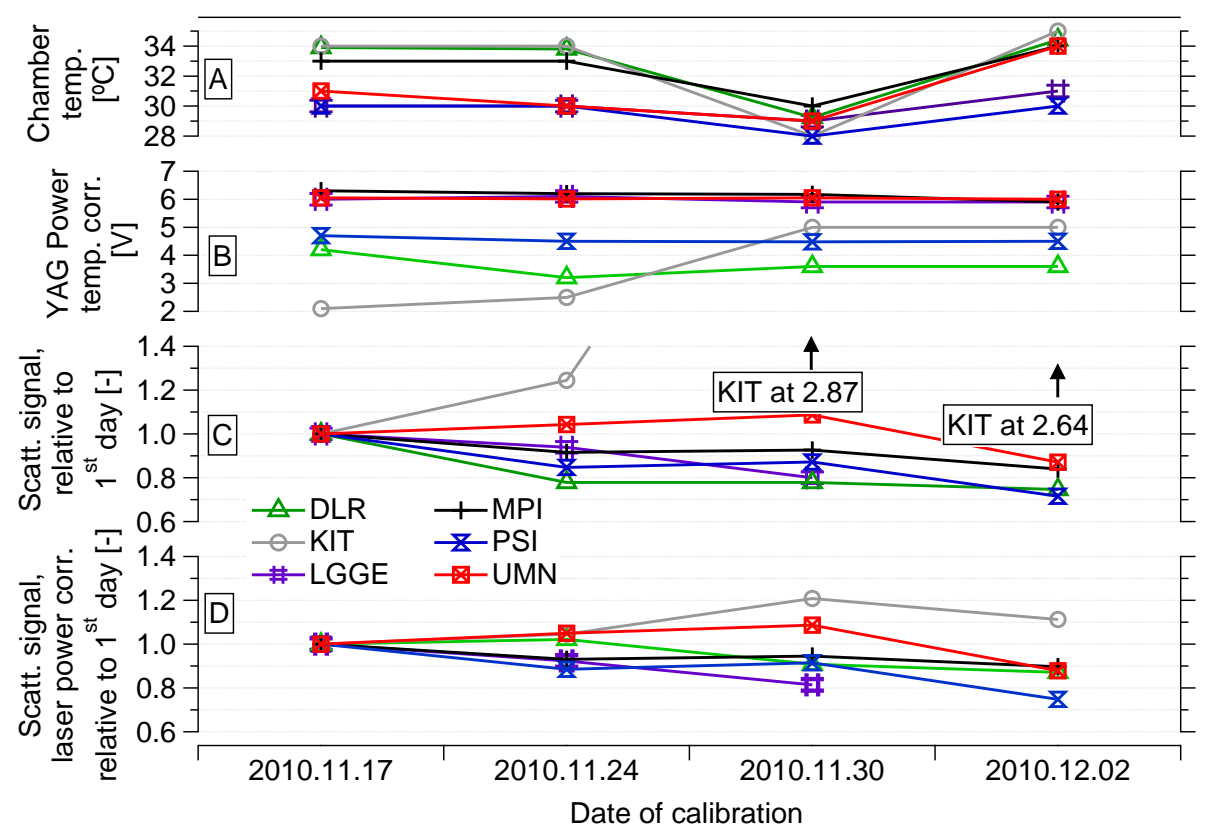

Fig. 3. Scattering detector calibration results, using PSL particles with a diameter of $269 \mathrm{~nm}$ ( $220 \mathrm{~nm}$ for LGGE). (A) Chamber temperature during calibration. (B) YAG power (laser power monitor) corrected for temperature variations (Sect. 4.1.2). (C) Relative drift of the scattering detector signal to the first calibration day (not accounting for laser power change). (D) Relative drift of the scattering detector signal to the first calibration day, divided by laser power, hence accounting for laser power change.

causing a decrease of the laser power to which the particles are exposed.

The LGGE SP2 also experienced a calibration drift of $\sim 20 \%$ during the first three calibrations (fourth calibration is missing) without a parallel integrated laser power drift. Part of this rather fast drift can possibly be caused by a laser position shift.

In summary, it can be said that drifts of the scattering calibration of up to $\sim 20 \%$ within 16 days must be expected also for "stable" SP2s, while even larger drifts can occur for various reasons. This highlights the importance of a frequent scattering detector calibration in order to ensure data quality and to identify alignment problems. It has to be added that light scattering is strongly diameter dependent, such that an uncertainty of $20 \%$ in scattering amplitude still provides decently accurate optical sizing.

\subsubsection{Counting efficiency}

BC mass concentration measurements using the SP2 rely on quantitative measurement of $\mathrm{BC}$ mass in single particles and $100 \%$ detection efficiency of sampled particles within the practical size range of the instrument. The former condition is assured by calibrating the incandescence signal amplitude with "BC mass standards" (Sects. 3.2 and 4.1.1); the latter can be verified by comparing the particle number concentration measured by the SP2 against a CPC.

Various phenomena can lower the counting efficiency and have been studied in Schwarz et al. (2010). Briefly, the first limitation to the SP2 detection of BC number and/or mass arises from the physical process inherent in the SP2 detection technique - namely at small BC mass or low laser intensities, particles fail to heat to vaporization, a requirement for proper detection. Once the particle has reached incandescence, the incandescence peak height still has to be resolved in order for the particle to be counted. The detection of the peak height depends on the baseline noise, the electronic signal amplification and the A/D converter's resolution. In addition, the SP2 data acquisition software can discard small $\mathrm{BC}$ mass particles if the user-defined signal threshold, above which the SP2 triggers the signal of a particle, is set to a value much higher than the baseline noise.

Figure 4 presents the counting efficiency of the SP2s for the fullerene soot calibration aerosol, calculated relative to the number concentration measured by the CPC. The influence of multiply charged particles, which can easily be distinguished from singly charged particles by the SP2, is corrected by subtracting the number concentration of multiply charged particles from both the SP2 and CPC measurement (i.e. assuming unit counting efficiency for multiply charged particles as they are bigger).

The results show a $100 \%$ counting efficiency down to $1 \mathrm{fg}$ $\left(D_{\mathrm{MEV}} \sim 100 \mathrm{~nm}\right)$ for all the SP2s when the laser power was sufficiently high and the detector block was aligned (Fig. 4; solid lines). Below this diameter, the discrepancy between instruments increases. In order to accurately compare the different counting efficiencies, the threshold diameter 


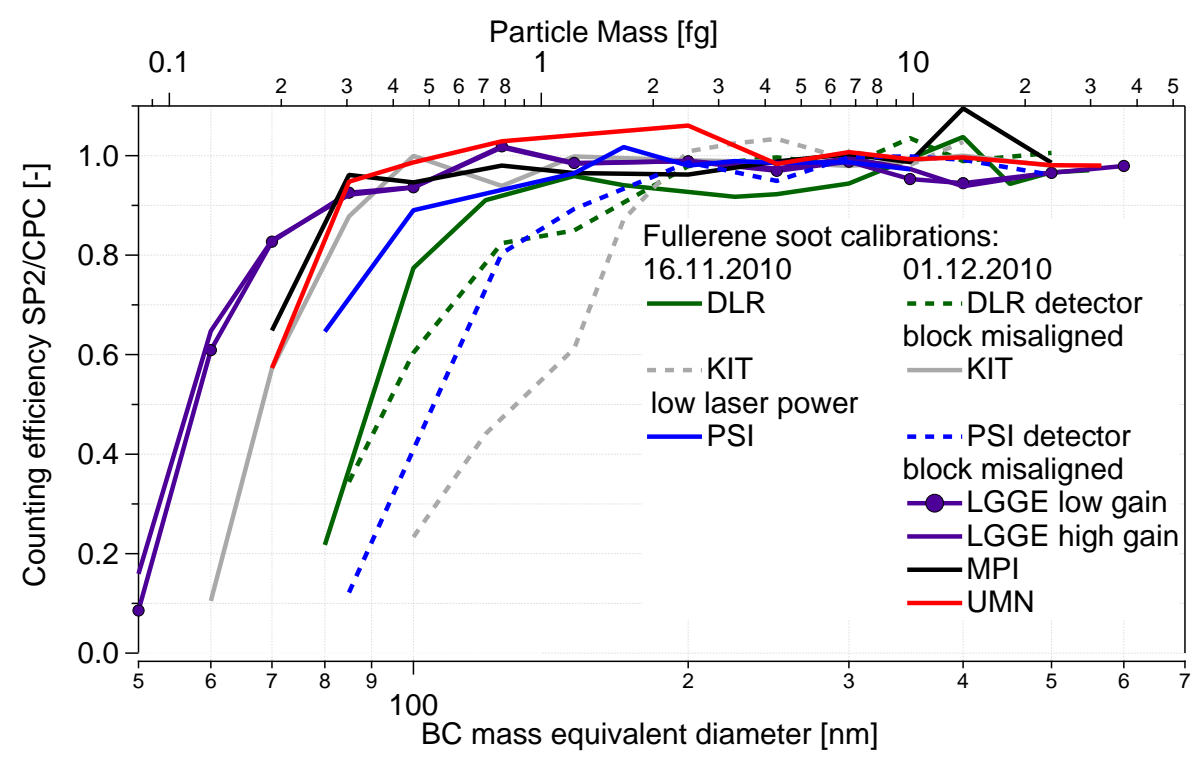

Fig. 4. Counting efficiency of the SP2s for fullerene soot measured on 16 November 2010 and 1 December 2010. The counting efficiency is here defined as the number of singly charged particles measured by the SP2 over that measured by the CPC as a function of the particle mass equivalent diameter (Sect. 4.1.3). The dashed-line style indicates that the counting efficiency is affected by a misalignment.

$\left(D_{50}\right)$ at which the detection efficiency is $50 \%$ was determined for all SP2s by fitting a sigmoid curve to the data points (note: these diameter values represent mass equivalent diameters which are calculated from the BC mass, assuming a bulk material density of $1800 \mathrm{~kg} \mathrm{~m}^{-3}$ ). LGGE's SP2 gets the lowest lower detection limit (LDL) with a $D_{50}$ of $\sim$ $57 \mathrm{~nm}(0.2 \mathrm{fg})$. This can be considered as an upper limit of the physical incandescence threshold mentioned above (at this laser power). Schwarz et al. (2010) reported a higher LDL of $0.7 \mathrm{fg}$. This discrepancy may be the result of the superior laser power of the LGGE SP2 to that achieved by Schwarz et al. (2010). The similitude between low- (Fig. 4; purple line and markers) and high-gain (Fig. 4; purple line, no markers) counting efficiencies can be either the result of the physical incandescence threshold or a too high baseline noise limiting the detection of smaller BC particles. However, we cannot exclude that the nebulizer also produces a small fraction of purely scattering particles of this size which would not be detected by the SP2, but would contribute to the total number concentration detected by the CPC.

Considering only the well aligned instruments (Fig. 4; solid lines), MPI, UMN and KIT SP2s have similar counting efficiency $\left(D_{50} \sim 67 \mathrm{~nm}\right)$, while PSI's SP2 is a little less efficient $\left(D_{50} \sim 80 \mathrm{~nm}\right)$ followed by DLR's instrument $\left(D_{50} \sim 90 \mathrm{~nm}\right)$. PSI and DLR's SP2s might be on the low side as they have the most unfortunate ratio between gain and A/D converter resolution (in favour of a higher upper detection limit). The dashed lines in Fig. 4 are affected by misalignment between laser beam and particle beam or insufficient laser power. The counting efficiencies in these cases drop down significantly for small BC cores.
This result highlights the importance of having a careful instrument tuning and of sufficient laser power when it comes to detection of small BC cores. In general, the counting efficiency check is important to identify the LDL and potential alignment issues, as well as to optimize the amplification gain for the intended measurement use. However, such counting efficiency curves should not be used to correct measurements in the cut off range (other than for sensitivity analyses), as the exact shape may, for example, depend on particle morphology, mixing state, or ambient pressure (i.e. during aircraft measurements).

\subsection{BC core number concentration determination}

One of the advantages of the SP2 is its capability to quantify the BC mass content of each single particle sampled, thereby obtaining the number and mass size distributions of the BC cores independently of their mixing state.

The reproducibility of the $\mathrm{BC}$ core number size distribution measurement is investigated by comparing measurements of all the SP2s for an ambient air sample taken on 2 December 2010. Figure 5 shows that above a $D_{\mathrm{MEV}}$ of $100 \mathrm{~nm}$, the agreement between SP2s is within $\pm 5 \%$ of the average size distribution (excluding DLR's). Below $100 \mathrm{~nm}$, the difference between size distributions is increasing. Part of this disagreement can be explained by, for example, dropping counting efficiency of PSI's SP2, which was misaligned on this day (see Sect. 4.1.3). The disagreement observed for the DLR SP2 across the whole range is however not consistent with the rather high counting efficiency previously shown in Fig. 4 and Sect. 4.1.3. The reasons for the systematic undercounting of DLR's SP2 during this experiment could not 


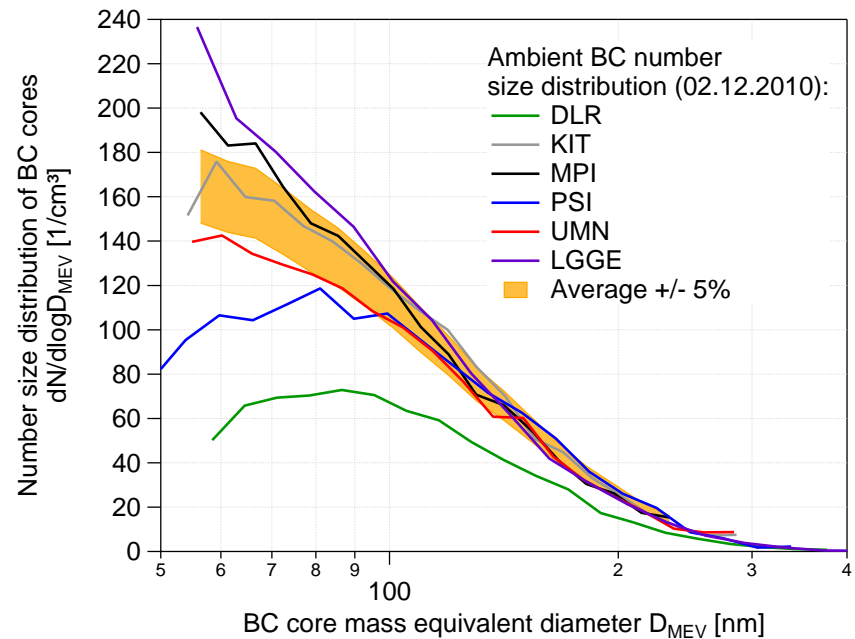

Fig. 5. Comparison of BC core number size distributions of an ambient air sample as measured by the SP2s. The reasons for the systematic undercounting of DLR's SP2 during this experiment could not be definitely identified. However, DLR's SP2 was measuring correctly during most other experiments.

be definitely identified. However, DLR's SP2 was measuring correctly during most other experiments, as shown later.

The accuracy of the $\mathrm{BC}$ core number concentration determination was also investigated using CAST soot (Fig. 6). The CAST soot experiment ran from 23 November until 24 November. The soot particles were introduced into the empty AIDA chamber and let coagulate overnight. The coagulation led to a decrease in particle number concentration and an increase of the particle diameters (the modal mobility diameter shifted from 70 to $250 \mathrm{~nm}$, according to the SMPS). Part of the decrease in number concentration is due to wall losses and the constant dilution of the AIDA chamber air in order to keep a constant pressure. The large and sudden decrease in number concentration observed in the early morning of the 24th was due to a failure of the dilution stages in the sampling line. $\alpha$-pinene and ozone were introduced on 24 November at 01:34 p.m. and at 03:05 p.m. to form SOA which condensed on the particles. The SP2 number concentration was tested against the CPC's number concentration (Fig. 6). Initially, all the SP2s measured lower than the CPC because a substantial fraction of the CAST soot particles (still uncoated) was smaller than the SP2's lower detection limit. The discrepancy between CPC and SP2s then decreased as the particles grew. Once the particles were big enough to be detected by all the SP2s, the average number concentration agreed with the CPC number concentration within $\pm 7 \%$ (Fig. 6b), excluding DLR's SP2 which remained a little lower (by $10 \%$ ) probably due to the lower laser power (Sect. 4.1.2).

As a conclusion, we can say that accurate number concentration $( \pm 7 \%)$ and reproducible number size distribution $( \pm 5 \%)$ measurements can be achieved for BC cores bigger than $D_{\mathrm{MEV}}=100 \mathrm{~nm}(\sim 1 \mathrm{fg})$, independently of the type of particles sampled, with the caveats that the SP2 is properly adjusted and operated and that it has sufficient laser intensity. However, uncertainties increase below this diameter and depend a lot on careful instrument adjustment.

\subsection{BC mass concentration determination}

The reproducibility of the $\mathrm{BC}$ mass determination was tested using diesel car exhaust particles. Figure 7 shows that the BC mass size distributions of diesel soot measured by all SP2s agree within $\pm 10 \%$ above $D_{\mathrm{MEV}}=90 \mathrm{~nm}$.

Below this diameter, the difference increases to $\sim 20 \%$ at $70 \mathrm{~nm}$. This increased uncertainty can again be explained by counting efficiency effects, but is probably also due to a higher calibration uncertainty at small BC mass. As an example, MPI and UMN's SP2s measure an equal number concentration (Fig. 6) but different mass concentration for CAST soot (Fig. 9). This discrepancy can only be explained by a difference in accuracy of the BC mass calibration.

The effect of additional SOA coating on the BC core mass size distribution measurement was investigated with the CAST soot experiment also discussed in Sects. 4.2 and 4.5, as well as Figs. 6, 9 and 12. Figure 8 shows the BC core mass size distributions measured just before (01:30 p.m.) and just after the first coating step (02:00 p.m.). This coating step was estimated (from the SP2 data, Sect. 4.5) to increase the coating thickness of the BC cores with diameters between 200 $250 \mathrm{~nm}$ from $\sim 25 \mathrm{~nm}$ to $\sim 50 \mathrm{~nm}$ (Fig. 12). The BC core mass size distributions measured for the CAST soot agree between the SP2s, as shown above for the diesel soot (Fig. 7). The difference of the averaged distribution before and after the coating step is as small as 5\%. Furthermore, this $5 \%$ decrease can for the most part be explained by the continuous dilution of the AIDA chamber during the $30 \mathrm{~min}$ between the two measurements. Absence of influence of the coating steps on counting efficiency and $\mathrm{BC}$ mass quantification during this experiment is further confirmed with Figs. 6 and 9. These results confirm that the SP2 is able to detect the $\mathrm{BC}$ core mass size distribution with high reproducibility and without interference from non-refractory coatings. The latter has been shown in previous studies (Moteki and Kondo, 2007; Slowik et al., 2007; Cross et al., 2011).

The absolute $\mathrm{BC}$ mass as measured by the SP2 has also been compared to other techniques. Verifying the accuracy of the SP2's BC mass concentration measurements is complicated by the fact that no absolute reference method is available for $\mathrm{BC}$ or $\mathrm{EC}$ mass concentration measurements of BC particles with organic coatings. In Fig. 9, we report the comparison between EC mass concentration measurements obtained from offline analysis of filter samples using a Sunset analyzer (thermo-optical method) for the CAST soot experiment previously described. The average SP2 BC mass concentration is found to be around $10 \%$ higher than the Sunset's EC value. This difference is well within the 


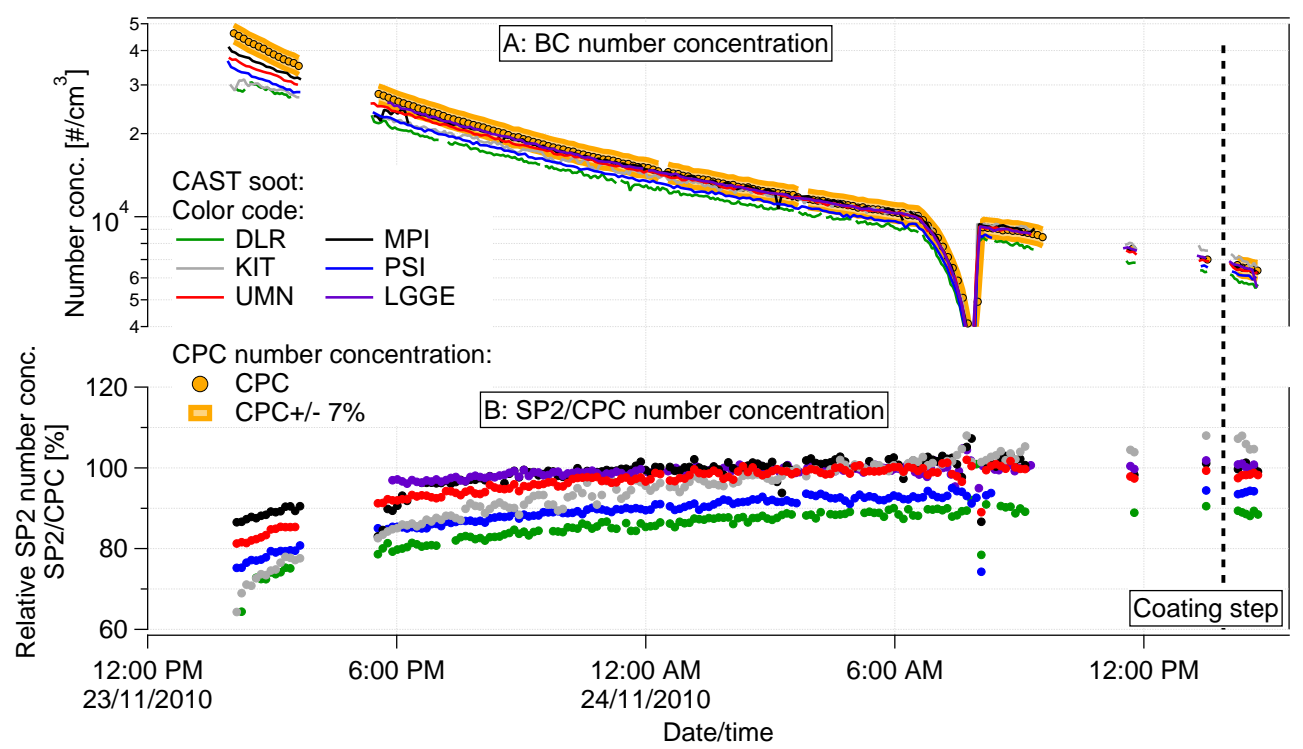

Fig. 6. (A) Particle number concentration time series of CAST soot as measured by the SP2s (lines) and the CPC (yellow circular markers). The shading corresponds to $\pm 7 \%$ of the CPC number concentration. (B) Ratio of SP2 to CPC number concentration measurements.

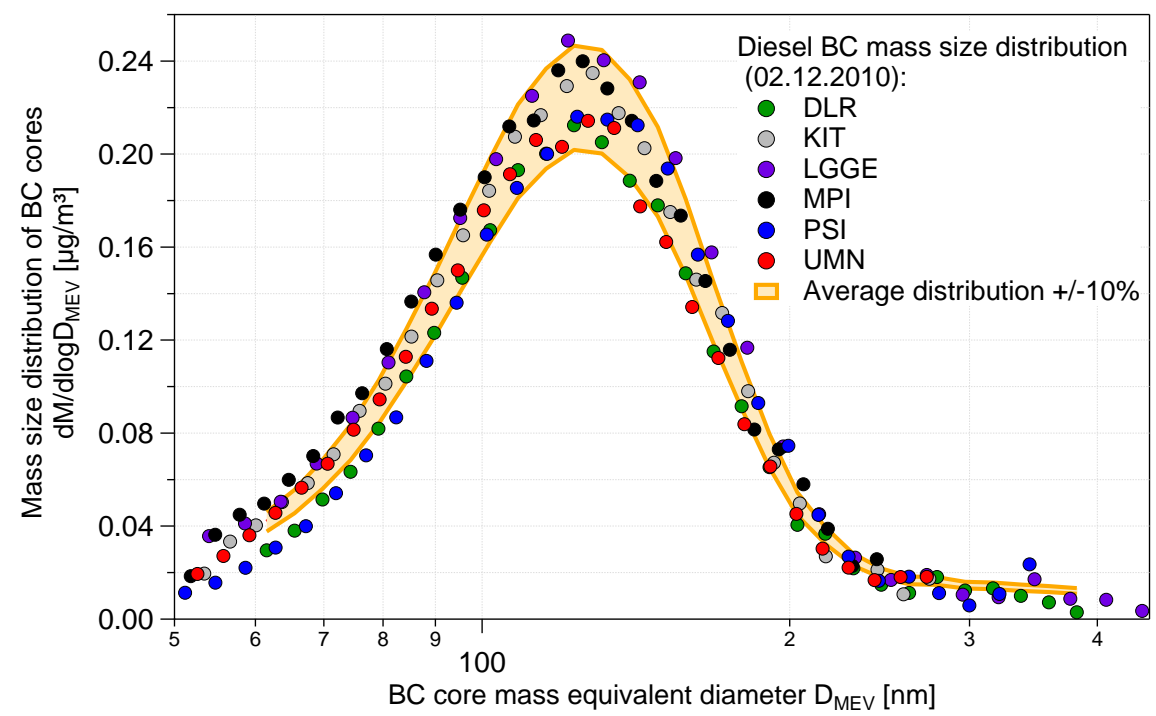

Fig. 7. Comparison of BC core mass size distributions of diesel car exhaust as measured by the SP2s.

uncertainties of the two methods. This gives clear evidence that the fullerene soot calibration of the SP2, which has been shown to be suitable for ambient and diesel soot (Moteki and Kondo, 2010; Laborde et al., 2012), can also be applied for CAST soot. However, a similar experimental setup as in Moteki and Kondo (2010) or Laborde et al. (2012), using an aerosol particle mass analyser should be used to measure the SP2's sensitivity to BC in CAST soot in order to confirm this result.

The comparison of the photoacoustic spectrometry (PAS) measurements with independent $\mathrm{BC}$ mass concentration measurements is commonly used to determine the mass ab- sorption coefficient (MAC) of BC matter. PAS measurements were available for parts of the CAST soot experiment shown in Fig. 9. Assuming a MAC of $12.5 \mathrm{~m}^{2} \mathrm{~g}^{-1} \mathrm{BC}$ (at $\lambda=532 \mathrm{~nm}$ ) brings the PAS mass concentration into agreement with the SP2 average mass concentration (a MAC of $14.5 \mathrm{~m}^{2} \mathrm{~g}^{-1} \mathrm{BC}$ would bring it into agreement with the $\mathrm{EC}$ measurement). This value is higher than the value of $\sim 5.5 \mathrm{~m}^{2} \mathrm{~g}^{-1} \mathrm{TC}$ found by Schnaiter et al. (2006). Part of this difference can be explained by the presence of a large amount of OC ( $60 \%$ during this experiment) and/or by a nonnegligible absorption coefficient of the OC material. Indeed, 


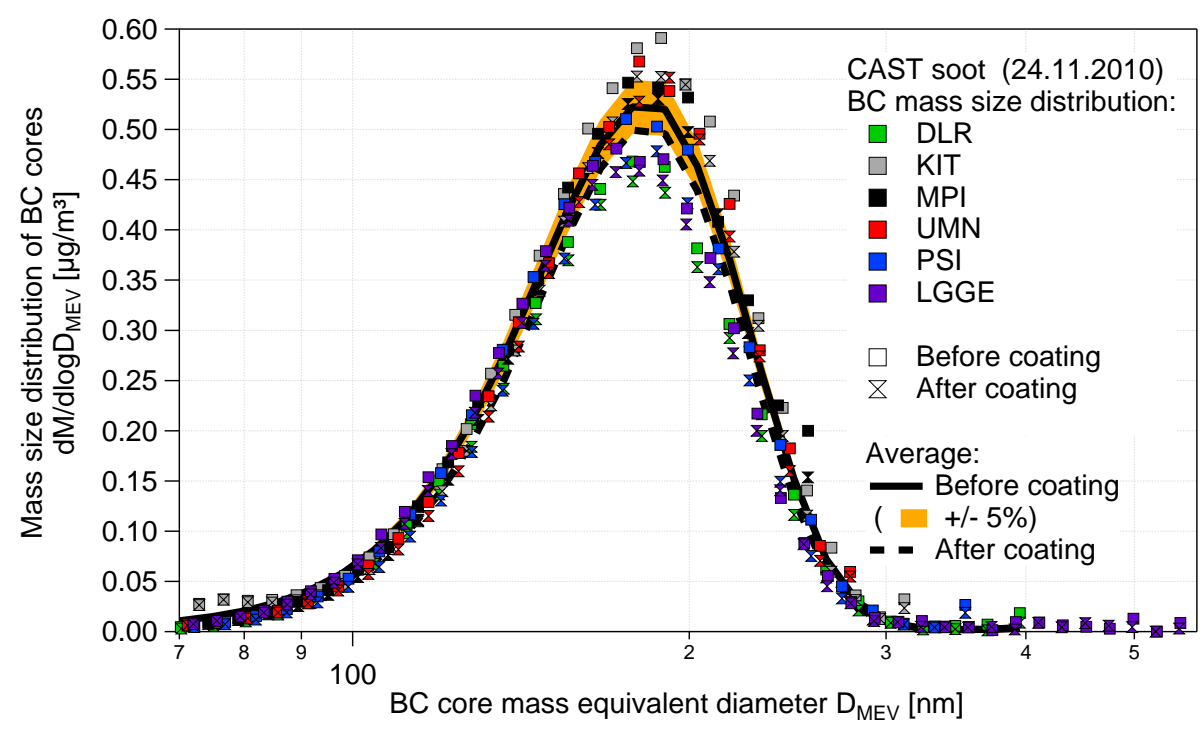

Fig. 8. Coating effect on the SP2 mass measurement: CAST soot mass size distribution before (square markers) and after (butterfly markers) the first coating step. This coating step was estimated to increase the coating thickness of the BC cores with diameters between 200-250 nm from $\sim 25 \mathrm{~nm}$ to $\sim 50 \mathrm{~nm}$.

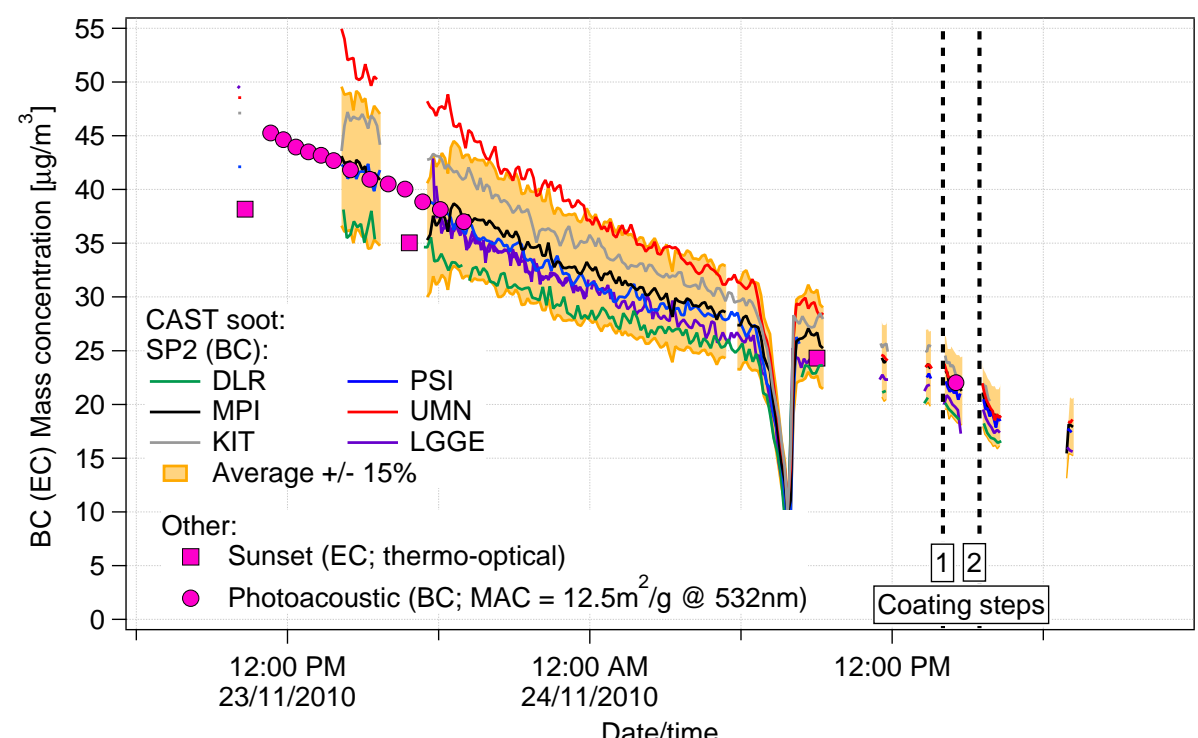

Fig. 9. BC (EC) mass concentration time series of CAST soot as measured by the SP2s (lines) and the Sunset analyser (square markers), and as inferred from the photoacoustic sensor (PAS; circular markers, assuming a mass absorption coefficient (MAC) of $12.5 \mathrm{~m}^{2} \mathrm{~g}^{-1} \mathrm{BC}$ at the PAS wavelength of $532 \mathrm{~nm}$ ). The shading corresponds to $\pm 15 \%$ of the SP2s average concentration.

the MAC value in Schnaiter et al. (2006) was calculated using TC values while $\mathrm{BC}(\mathrm{EC})$ values were used for this study.

The comparison of the SP2 BC mass with the Sunset thermo-optical EC and the calculated MAC values should not be affected by the limited detection range of the SP2, as the mass size distribution of the CAST soot used for this comparison was well within the detection range of the SP2. The results presented in this section indicate the accuracy of the SP2's BC measurement. However, the choice of calibra- tion material influences the measured $\mathrm{BC}$ mass concentration value and thus determines the accuracy of the SP2 measurement. The influence of the calibration material on the resulting BC mass measured by the SP2 will be discussed in detail in Sect. 5.

\subsection{Optical sizing of purely scattering particles}

The reproducibility of the optical sizing using the SP2's scattering signal was tested using a polydisperse aerosol 
of spherical and purely scattering SOA particles. The SOA aerosol was generated by ozonolysis of $\alpha$-pinene precursor gas in the AIDA chamber as explained in Sect. 2.2.3. The comparison of the SOA particle number size distributions measured by the SP2s, shown in Fig. 10, reveals good agreement $( \pm 15 \%)$.

The lower detection limit for optical sizing differed quite a bit between the different instruments. This is mainly caused by different detector sensitivity and laser power, as well as different baseline noise and trigger levels for data recording. Identifying the exact detection limits for a certain data set requires careful consideration of all these parameters.

As explained in Sect. 3.3, the SP2's scattering measurement is calibrated at a single particle size using a PSL size standard. The validity of this data analysis approach can be verified by comparing the SP2 measurements against the number size distribution measured by an SMPS. The SMPS sizes particles by their mobility diameter, which is equal to the volume equivalent diameter for spherical SOA particles. Optical diameters derived from the SP2's scattering measurement are also volume equivalent diameters; however, absolute values will depend on the refractive index assumed to translate the measured scattering cross section to a corresponding optical diameter. This fact can actually be used to estimate the refractive index of the SOA particles by fitting the refractive index to achieve best match with the SMPS measurement. Moteki et al. (2010) previously applied a similar method to the SP2 data to infer optical properties of BC particles. Good agreement between SMPS and SP2 across the whole size distribution was found for a RI of $n=1.35-0 i$ at a wavelength of $1064 \mathrm{~nm}$. This value is consistent with values reported by Nakayama et al. (2010) $(n=1.41-0 i$ at $\lambda=532 \mathrm{~nm}$ and $n=1.458-0 i$ at $\lambda=355 \mathrm{~nm}$ ) but is lower than the one reported by Schnaiter et al. (2005), both for SOA from $\alpha$-pinene ozonolysis. In summary, the reproducibility of SP2 measurements of the number size distribution of purely scattering particles is $\pm 15 \%$, and a SOA RI close to literature value was found, indicating absolute accuracy of the optical sizing too.

\subsection{Thickness of non-refractory coatings on BC particles}

Accurate BC mass measurement (Sect. 4.3) and optical sizing (Sect. 4.4) are prerequisites for estimating the thickness of non-refractory coatings on $\mathrm{BC}$ particles by combining the calculated optical diameter of the whole particle and the mass equivalent diameter of the $\mathrm{BC}$ core with a concentric coated sphere Mie model. The optical sizing of BC containing particles is more complicated than for purely scattering particles, as it can only be done from the leading edge (as described in Sect. 3.3) of the scattering signal due to evaporation of absorbing particles in the laser beam.

A first comparison of coating thickness measurements is reported in Fig. 11 for an ambient air sample taken during
10 min on 2 December 2010. The normalized histograms of coating thickness for individual BC particles agree well between the SP2s (solid lines). The minimum $(150 \mathrm{~nm})$ and maximum $(400 \mathrm{~nm})$ mass equivalent diameters of the $\mathrm{BC}$ cores included in this comparison were chosen such that the optical diameters of the whole coated particles were in between the lower and upper LEO-fit detection limits of the least and most sensitive instruments, respectively. The averaged coating thickness (Fig. 11; dashed lines) agrees within $\pm 17 \%$ between the SP2s.

A second comparison of observed coating thickness is done for the long CAST soot experiment performed on 2324 November 2010. The temporal evolution of the median coating thickness is reported in Fig. 12 for BC particles with a core diameter in between $200 \mathrm{~nm}$ and $250 \mathrm{~nm}$ as measured by $5 \mathrm{SP} 2 \mathrm{~s}$. The measured coating thickness $\Delta_{\text {coat }}$ remains essentially constant at $\Delta_{\text {coat }} \sim 20 \mathrm{~nm}$ during the initial phase of the experiment, where only coagulation occurs, and it increases substantially during the two coating steps, eventually reaching $\Delta_{\text {coat }} \sim 120-150 \mathrm{~nm}$. The agreement between SP2s is found to be within $\pm 15 \%$ (excluding KIT's SP2) for a coating between $\sim 20 \mathrm{~nm}$ and $\sim 150 \mathrm{~nm}$. The TEAPD of the LGGE SP2 was misaligned on this day, preventing reliable coating thickness measurements. However, the coating thickness measured by the LGGE SP2 was reliable when the split point was resolved, e.g. for the ambient sample discussed above (Fig. 11). The KIT's SP2 coating thickness is consistently lower than the other values. The BC core size distribution and the optical sizing of the purely scattering particles measured by KIT's SP2 agree with the results obtained from the other SP2s. Consequently, the coating thickness measurements should also agree. However, we speculate here that the coating thickness bias of KIT's SP2 is due to the low laser power on this day (Sect. 4.1.2), also considering the fact that the KIT SP2 agrees with all the other instruments when the laser power was sufficiently high (i.e. during the first comparison, Fig. 11).

Absolute verification of the coating thickness values is generally difficult and not possible with the data set available in this study. However, a basic comparison with the EC/TC value from the thermo-optical measurement can be done. The $\mathrm{BC}$ mass fraction $\varepsilon_{\mathrm{BC}}$ of each particle was calculated from the SP2 measurement performed on 24 November, using the following equation:

$$
\varepsilon_{\mathrm{BC}}=\frac{D_{\mathrm{MEV}}^{3} \rho_{\mathrm{BC}}}{D_{\mathrm{MEV}}^{3} \rho_{\mathrm{BC}}+\left\{\left(D_{\mathrm{MEV}}+2 \Delta_{\mathrm{coat}}\right)^{3}-D_{\mathrm{MEV}}^{3}\right\} \rho_{\mathrm{OC}}} .
$$

$D_{\mathrm{MEV}}$ is the BC core mass equivalent diameter, $\Delta_{\text {coat }}$ is the coating thickness, $\rho_{\mathrm{OC}}$ is the SOA density and $\rho_{\mathrm{BC}}$ is the void-free BC material density $\left(1800 \mathrm{~kg} \mathrm{~m}^{-3}\right.$; Moteki and Kondo, 2010). The organic coating of the untreated CAST soot can be expected to be dominated by aliphatics and polycyclic aromatic hydrocarbons (PAH; Slowik et al., 2007). Therefore, we assume density of $\rho_{\mathrm{OC}}=1000 \mathrm{~kg} \mathrm{~m}^{-3}$ for the 


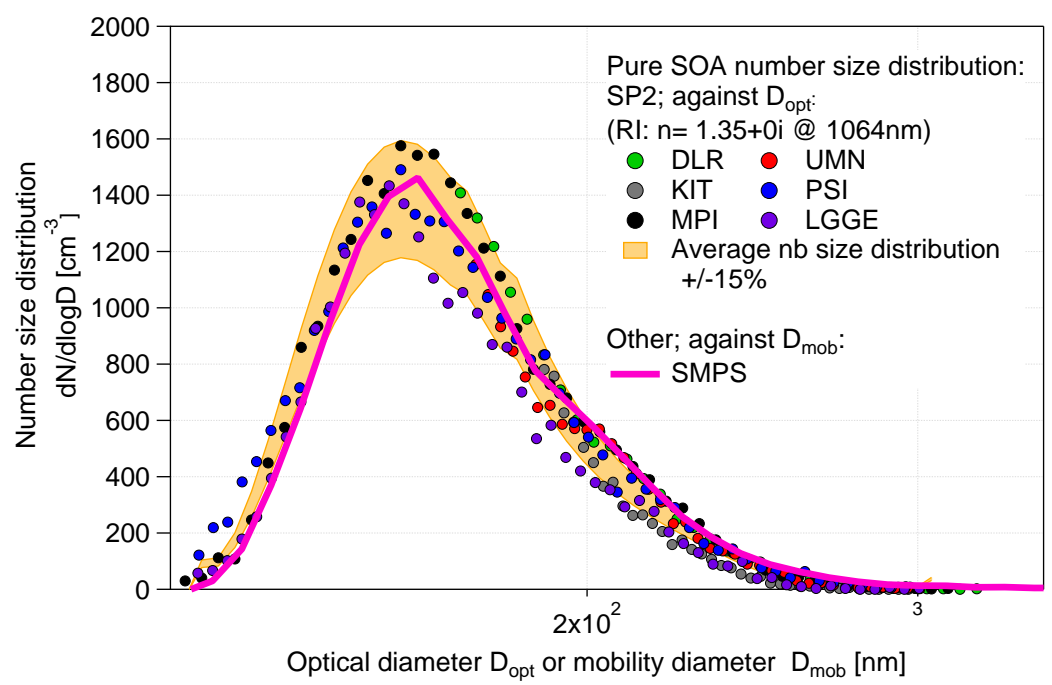

Fig. 10. Number size distribution of pure SOA particles as measured by the SP2s (markers; plotted against optical diameter) and the SMPS (line; plotted against mobility diameter). The shading represents the SP2s' average number size distribution $\pm 15 \%$. A refractive index of $n=1.35+0 i$ at the laser's wavelength of $1064 \mathrm{~nm}$ was used to calculate the optical diameter of the SOA particles from the differential scattering cross section measured by the SP2s.

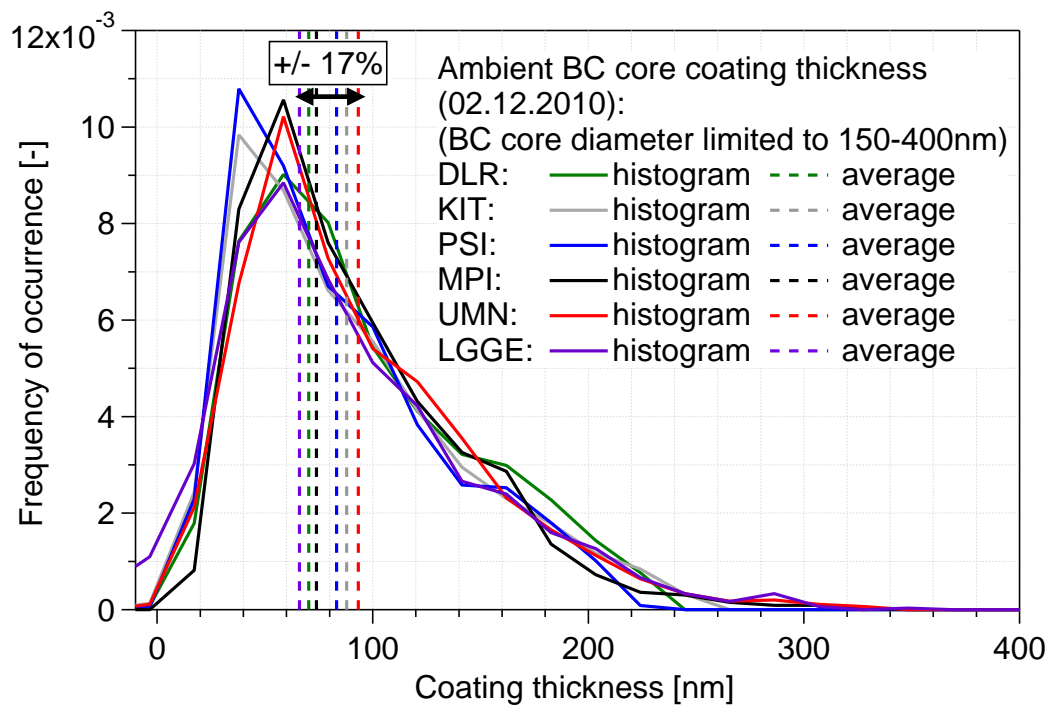

Fig. 11. Normalised histogram of coating thickness of ambient BC cores (sampled on 2 December) by non-refractory matter for particles with a $\mathrm{BC}$ core mass equivalent diameter in between $150 \mathrm{~nm}$ and $400 \mathrm{~nm}$. A refractive index of $n=2.26+1.26 i$, at the laser's wavelength of $1064 \mathrm{~nm}$, for the BC core was used, while a refractive index of $n=1.5$ was used for the non-refractory coating to calculate the coating thickness (see Sect. 3.3 for more details).

organic coating. The $\mathrm{EC}$ mass fraction, $\varepsilon_{\mathrm{EC}}$, is approximately equal to the thermo-optical EC/TC measurement (Sunset) as the mass of the organic matter is almost equal to the mass of organic carbon.

$\varepsilon_{\mathrm{BC}}$ from the SP2 can then be directly compared to the $\varepsilon_{\mathrm{EC}}$ value from the Sunset instrument. The two methods agree within $\sim 15 \%$ (Table 5). This shows that the coating thickness measurement is also meaningful in absolute terms. However, it will always remain of semi-quantitative nature as assumptions on the morphology and refractive indices of BC core and non-refractory coating have to be made in the Mie calculations (see Sect. 3.3).

\section{Calibration material influence}

Aquadag and fullerene soot are two common SP2 calibration materials. The difference in the SP2 sensitivity to these two materials has been investigated by several research groups 


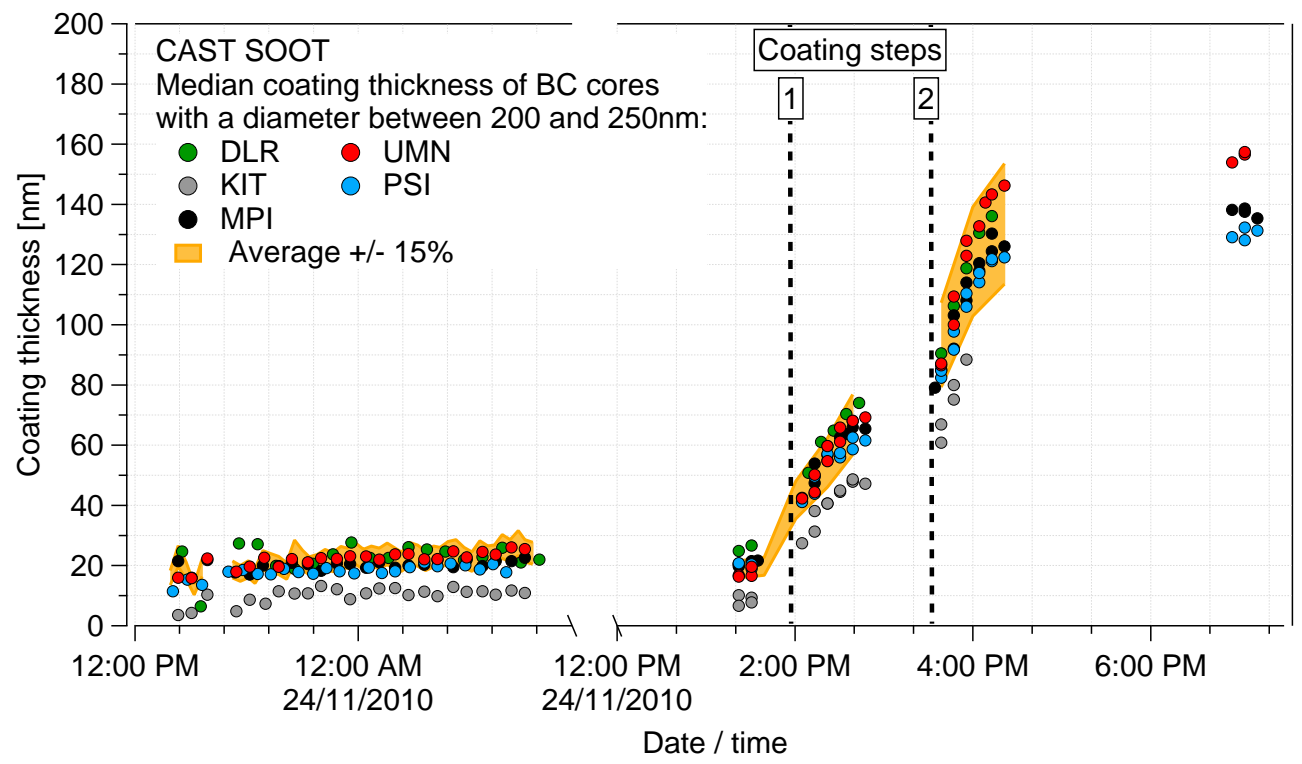

Fig. 12. Coating thickness of non-refractory matter on CAST soot BC cores. Time series of the coating thickness average for $5 \mathrm{SP} 2 \mathrm{~s} \pm 15 \%$. A refractive index of $n=1.9+0.8 i$, at the laser's wavelength of $1064 \mathrm{~nm}$, for the BC core was used, while a refractive index of $n=1.5$ was used for the non-refractory coating to calculate the coating thickness (see Sect. 3.3 for more details). LGGE's SP2 is not included in this graph as the LEO-fit could not be performed (detection of the particle's position was unreliable as the TEAPD was not well adjusted).

Table 5. Composition of the CAST soot from the experiment conducted on 23-24 November 2010. Total carbon (TC), organic carbon (OC) and elemental carbon (EC) were measured by thermooptical analysis (Sunset). The mass fraction of EC $\left(\varepsilon_{\mathrm{EC}}\right)$ is approximately equal to $\mathrm{EC} / \mathrm{TC}$ as the mass of the organic matter is almost equal to the mass of organic carbon. The mass fraction of $\mathrm{BC}\left(\varepsilon_{\mathrm{BC}}\right)$ is calculated from the SP2's coating thickness measurement using Eq. (1). $\varepsilon_{\mathrm{EC}}$ from the Sunset and $\varepsilon_{\mathrm{BC}}$ from the SP2 should be comparable.

\begin{tabular}{lccc}
\hline Date/time & $\begin{array}{c}\text { OC/TC } \\
\text { Sunset }\end{array}$ & $\begin{array}{c}\varepsilon_{\mathrm{EC}} \approx \mathrm{EC} / \mathrm{TC} \\
\text { Sunset }\end{array}$ & $\begin{array}{c}\varepsilon_{\mathrm{BC}} \\
\mathrm{SP} 2\end{array}$ \\
\hline 23 Nov. 2010 10:19 & 0.62 & 0.38 & Not available \\
23 Nov. 2010 16:50 & 0.64 & 0.36 & 0.3 \\
24 Nov. 2010 09:01 & 0.61 & 0.39 & 0.35 \\
\hline
\end{tabular}

(Moteki and Kondo, 2010; Laborde et al., 2012). It was shown that the SP2 is more sensitive to Aquadag than to fullerene soot and that the fullerene soot calibration agrees better with the SP2's sensitivity to BC from (thermally denuded) diesel car exhaust, log-wood burner exhaust and ambient particles (in locations with a dominant contribution of fossil fuel burning to BC mass). As a result, it was decided within the SP2 community, during a recent workshop, that fullerene soot should be the primary calibration standard for SP2 measurements (Baumgardner et al., 2012). However, many previous SP2 measurements rely on Aquadag calibrations. Therefore, it was also decided at the same workshop that Aquadag calibrations can be recalculated to a fullerene soot equivalent calibration using the approach proposed in
Baumgardner et al. (2012):

$S_{\mathrm{FSeq}}\left(m_{\mathrm{BC}}\right)=\frac{S_{\mathrm{AQ}}\left(m_{\mathrm{AQ}}\right)}{m_{\mathrm{AQ}}} r_{\mathrm{FS} 2 \mathrm{AQ}} m_{\mathrm{BC}}$.

$S_{\mathrm{FSeq}}$ is the fullerene soot equivalent SP2 signal amplitude as a function of $\mathrm{BC}$ mass $\left(m_{\mathrm{BC}}\right)$, i.e. the fullerene soot equivalent calibration curve. $S_{\mathrm{AQ}}$ is the measured SP2 incandescence signal amplitude for Aquadag as a function of Aquadag mass $\left(m_{\mathrm{AQ}}\right)$, i.e. the Aquadag calibration curve, and $r_{\mathrm{FS} 2 \mathrm{AQ}}$ is the ratio between the SP2's signal amplitudes for fullerene soot and Aquadag particles of equal mass.

Figure 13 shows the ratio of the SP2's sensitivity to Aquadag and fullerene soot as a function of particle mass for all SP2s involved in this study and three additional SP2s from the Earth System Research Laboratory at NOAA in Boulder.

The NOAA instruments have a modified narrowband incandescence detector (see also Sect. 2.1.1); however, the broadband incandescence detector, which is used here, is identical to the other 6 commercial instruments. The measurements shown in Fig. 13 are based on size-selected particles, and the corresponding particle mass was calculated from the mobility diameter using the effective density data reported in Gysel et al. (2011). The sensitivity ratio was found to be similar for all the SP2s for particle masses greater than $\sim 1 \mathrm{fg}$. A previous study (using only one SP2) has shown that the sensitivity ratio between Aquadag and fullerene soot at a mass of $8.9 \mathrm{fg}$, where BC mass size distributions of atmospheric aerosols typically peak (Schwarz et al., 2008), is $\sim 1.3$ (Laborde et al., 2012). This value is consistent with the present study where the mean sensitivity 


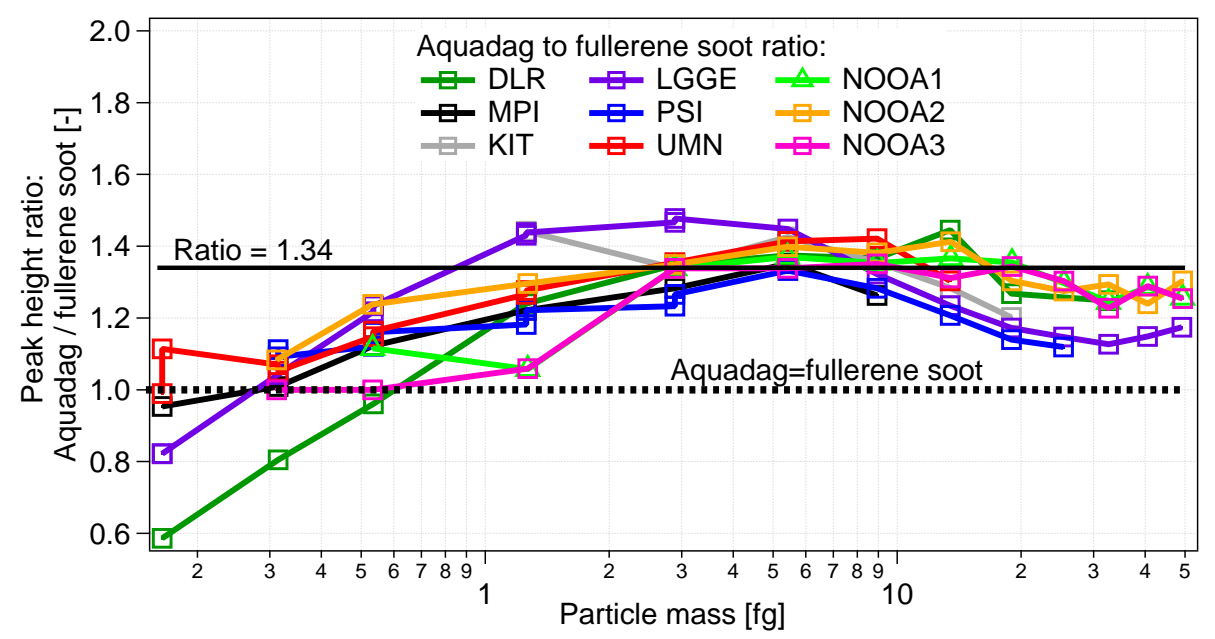

Fig. 13. SP2's sensitivity difference between Aquadag and fullerene soot, shown as a ratio of the broadband incandescence signals for particles of equal mass. Three additional SP2s from NOAA are included in this comparison (Sect. 5).

ratio of all $9 \mathrm{SP} 2 \mathrm{~s}$ was found to be $\sim 1.34$, which translates to an inverse sensitivity ratio of the SP2 sensitivity to fullerene soot and Aquadag of $r_{\mathrm{FS} 2 \mathrm{AQ}} \approx 0.75$ at a mass of $8.9 \mathrm{fg}$. This value of $r_{\mathrm{FS} 2 \mathrm{AQ}}$ is used in the recommendation by Baumgardner et al. (2012) for recalculating Aquadag calibrations to fullerene soot equivalent calibrations. This specific value of $r_{\mathrm{FS} 2 \mathrm{AQ}}$ is only valid for SP2s, using the same PMT and optical filter as detailed in Sect. 2.1.

The influence of the choice of calibration curve is clearly seen in Fig. 14a. The BC mass size distributions presented in Fig. 8 are repeated here by applying both the fullerene soot and the Aquadag calibration curves in the data analysis. Figure 14a clearly illustrates that consistent results are achieved with all SP2s, if the same calibration material is used. However, using the Aquadag calibration decreases the total mass concentration (area) by $\sim 30 \%$ and the modal diameter, inferred from BC mass per particle, shifts from $D_{\mathrm{MEV}} \approx 184$ to $D_{\mathrm{MEV}} \approx 165 \mathrm{~nm}$ compared to using the fullerene soot calibration.

Figure 14b repeats the fullerene soot calibrated BC mass size distributions from Fig. 14a and compares them with the results obtained by applying the fullerene soot equivalent Aquadag calibration, recalculated from the Aquadag calibration point at $8.9 \mathrm{fg}$ ( $300 \mathrm{~nm}$ mobility diameter) according to Eq. (2) and using $r_{\mathrm{FS} 2 \mathrm{AQ}}=0.75$ from above. The results from the two calibration approaches differ by less than $5 \%$ for all SP2s (considering one instrument at a time in Fig. 14b). The agreement between SP2s remains within the reproducibility $( \pm 10 \%)$ of the mass size distribution measurement already reported in Sect. 4.3. The scaled Aquadag calibration performs well down to small diameters $\left(D_{\mathrm{MEV}} \approx 100 \mathrm{~nm}\right.$ ), which is not self-evident given the simple scaling approach (Eq. 2). As a consequence, the method of applying a recalculated fullerene soot equivalent Aquadag calibration curve is a valid and reproducible calibration approach.
This raises the question about the accuracy and comparability of previous BC data reported from SP2s calibrated with Aquadag. The effective density of the calibration material has also to be considered in this context, as most SP2 calibrations were done by selecting the calibration particles by their mobility diameter, rather than their mass, with a constant assumed effective density. Factory calibrations of the SP2 used to be based on size selected Aquadag assuming a constant effective density of $1000 \mathrm{~kg} \mathrm{~m}^{-3}$. However, the effective density of an Aquadag particle with a mobility diameter of $300 \mathrm{~nm}$ is $\sim 633 \mathrm{~kg} \mathrm{~m}^{-3}$. Using a density of $1000 \mathrm{~kg} \mathrm{~m}^{-3}$ instead of $633 \mathrm{~kg} \mathrm{~m}^{-3}$ has the effect of scaling the Aquadag calibration curve with a factor 0.63, which is a little smaller than the value $r_{\mathrm{FS} 2 \mathrm{AQ}}=0.75$ promoted above, and thus brings the resulting calibration curve to $\sim 15 \%$ below the fullerene soot calibration. In conclusion, the original factory calibration of the SP2 is serendipitously close to the fullerene soot calibration now recommended by Baumgardner et al. (2012).

\section{Conclusions}

This study generally showed that all quantities measured by the SP2 are reproducible and quantitative (semi-quantitative for the coating thickness).

Tests using fullerene soot revealed unit detection efficiency above a BC core diameter of $D_{\mathrm{MEV}} \approx 100 \mathrm{~nm}(1 \mathrm{fg})$. This lower limit for unit counting efficiency can be extended further down to $0.2 \mathrm{fg}$ BC per particle when operating the SP2 with sufficient laser power and incandescence detector gain as well as with a good alignment of the laser optics and the detector block. Above $1 \mathrm{fg}, \mathrm{BC}$ core number and mass size distribution agree with each other within $\pm 5 \%$ and $\pm 10 \%$, respectively. In addition, the optical number size distribution of purely scattering particles measured by the SP2 


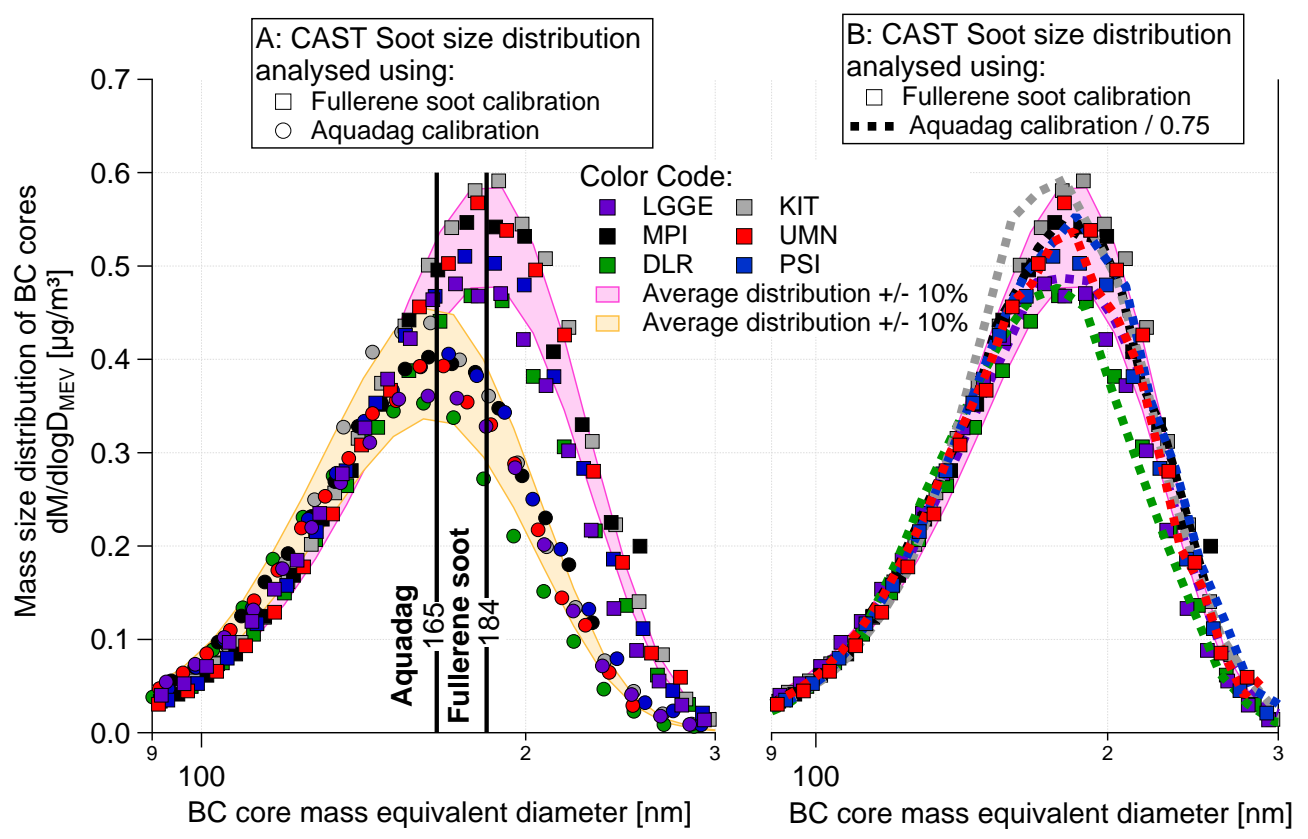

Fig. 14. BC core mass size distribution of CAST soot (24 November 2010) obtained from the SP2 measurements by applying the (A) fullerene soot calibration (square markers) and Aquadag calibration (circular markers) and (B) fullerene soot calibration (square markers) and fullerene soot equivalent calibration (dashed lines). The fullerene soot equivalent calibration was derived from the Aquadag calibration using Eq. (2).

was found to be reproducible within $\pm 15 \%$. However, frequent calibrations of the optical sizing are required in order to account for drifts of the relevant laser intensity.

The accuracy of the $\mathrm{BC}$ mass concentration depends on the selected calibration material. Previous studies showed that the SP2 is more sensitive to fullerene soot than to Aquadag and that fullerene soot should be used to calibrate the SP2 for atmospheric applications. A constant sensitivity ratio of 0.75 at $8.9 \mathrm{fg}$ was found in this study, for all $9 \mathrm{SP} 2 \mathrm{~s}$ compared, between the SP2 sensitivity to fullerene soot and Aquadag. This allows calculating a fullerene soot equivalent calibration from a measured Aquadag calibration. This method of recalculating an Aquadag calibration produced results in good agreement (within $\pm 5 \%$ ) with those obtained by directly applying a fullerene soot calibration.

The measured coating thickness was found to be reproducible (within $\pm 17 \%$ ). This result proves the robustness of the LEO-fit method used for the data analysis and could only be achieved due to the good agreement of the BC mass and optical size measurements. The estimated coating thickness was found to be consistent with thermo-optical EC/TC measurements. However, the coating thickness values are only considered to be semi-quantitative due to the need of numerous assumptions.

Generally the SP2 can really help in characterizing atmospheric $\mathrm{BC}$ due to its high reproducibility and accuracy. However, great care has to be taken in preparing the SP2 instrument as both accuracy and reproducibility are tightly linked to proper SP2 calibration and tuning.

\section{Supplementary material related to this article is available online at: http://www.atmos-meas-tech.net/5/ 3077/2012/amt-5-3077-2012-supplement.pdf.}

Acknowledgements. Funding was received from the EU through EUROCHAMP-2 program and the Swiss National Science Foundation. A. W. and the MPIC Mainz acknowledge funding from the German Research Foundation (DFG, SPP-1294 HALO, PO 1013/22). We thank E. Traxler (University of Vienna) for analyzing the filters with the Sunset analyzer. B. W. and DLR Oberpfaffenhofen acknowledge funding by the Helmholtz Association under grant number VH-NG-606 (Helmholtz-University Young Investigators Group AerCARE). The University of Manchester would like to acknowledge support from the UK Natural Environment Research Council through the MC4 project [Grant ref: NE/H008136/1]. O. M. acknowledges funding from the Deutsche Forschungsgemeinschaft (DFG, SPP1294 HALO project MO 668/1-2) received to operate the AIDA facility for instrument intercomparison. Setup and operation of the mobile diesel engine at the AIDA facility was funded by the Karlsruhe Institute of Technology (KIT) startup funds (STUB 2011).

Edited by: P. Herckes 


\section{References}

Baumgardner, D., Popovicheva, O., Allan, J., Bernardoni, V., Cao, J., Cavalli, F., Cozic, J., Diapouli, E., Eleftheriadis, K., Genberg, P. J., Gonzalez, C., Gysel, M., John, A., Kirchstetter, T. W., Kuhlbusch, T. A. J., Laborde, M., Lack, D., Müller, T., Niessner, R., Petzold, A., Piazzalunga, A., Putaud, J. P., Schwarz, J., Sheridan, P., Subramanian, R., Swietlicki, E., Valli, G., Vecchi, R., and Viana, M.: Soot reference materials for instrument calibration and intercomparisons: a workshop summary with recommendations, Atmos. Meas. Tech., 5, 1869-1887, doi:10.5194/amt-51869-2012, 2012.

Birch, M. E. and Cary, R. A.: Elemental carbon-based method for monitoring occupational exposures to particulate diesel exhaust, Aerosol Sci. Technol., 25, 221-241, 1996.

Bohren, C. F. and Huffman, D. R.: Absorption and Scattering of Light by Small Particles, Willey, New York, 1983.

Bond, T. C. and Bergstrom, R. W.: Light absorption by carbonaceous particles: An investigative review, Aerosol Sci. Technol., 40, 27-67, 2006.

Bond, T. C., Bhardwaj, E., Dong, R., Jogani, R., Jung, S. K., Roden, C., Streets, D. G., and Trautmann, N. M.: Historical emissions of black and organic carbon aerosol from energy-related combustion, 1850-2000, Global Biogeochem. Cy., 21, GB2018, doi:10.1029/2006GB002840, 2007.

Crawford, I., Möhler, O., Schnaiter, M., Saathoff, H., Liu, D., McMeeking, G., Linke, C., Flynn, M., Bower, K. N., Connolly, P. J., Gallagher, M. W., and Coe, H.: Studies of propane flame soot acting as heterogeneous ice nuclei in conjunction with single particle soot photometer measurements, Atmos. Chem. Phys., 11, 9549-9561, doi:10.5194/acp-11-9549-2011, 2011.

Cross, E. S., Onasch, T. B., Ahern, A., Wrobel, W., Slowik, J. G., Olfert, J., Lack, D. A., Massoli, P., Cappa, C. D., Schwarz, J. P., Spackman, J. R., Fahey, D. W., Sedlacek, A., Trimborn, A., Jayne, J. T., Freedman, A., Williams, L. R., Ng, N. L., Mazzoleni, C., Dubey, M., Brem, B., Kok, G., Subramanian, R., Freitag, S., Clarke, A., Thornhill, D., Marr, L. C., Kolb, C. E., Worsnop, D. R., and Davidovits, P.: Soot particle studies - Instrument intercomparison - project overview, Aerosol Sci. Technol., 44, 592611, 2011.

Droplet Measurement Technologies: Single particle soot photometer (SP2) - Operator manual, DOC-0171, Revision G-5, Describes the SP2-D, 2012.

Gao, R. S., Schwarz, J. P., Kelly, K. K., Fahey, D. W., Watts, L. A., Thompson, T. L., Spackman, J. R., Slowik, J. G., Cross, E. S., Han, J. H., Davidovits, P., Onasch, T. B., and Worsnop, D. R.: A novel method for estimating light-scattering properties of soot aerosols using a modified single-particle soot photometer, Aerosol Sci. Technol., 41, 125-135, 2007.

Gysel, M., Laborde, M., Olfert, J. S., Subramanian, R., and Gröhn, A. J.: Effective density of Aquadag and fullerene soot black carbon reference materials used for SP2 calibration, Atmos. Meas. Tech., 4, 2851-2858, doi:10.5194/amt-4-2851-2011, 2011.

Koch, D., Balkanski, Y., Bauer, S. E., Easter, R. C., Ferrachat, S., Ghan, S. J., Hoose, C., Iversen, T., Kirkevåg, A., Kristjansson, J. E., Liu, X., Lohmann, U., Menon, S., Quaas, J., Schulz, M., Seland, Ø., Takemura, T., and Yan, N.: Soot microphysical effects on liquid clouds, a multi-model investigation, Atmos. Chem. Phys., 11, 1051-1064, doi:10.5194/acp-11-1051-2011, 2011.
Kondo, Y., Sahu, L., Moteki, N., Khan, F., Takegawa, N., Liu, X., Koike, M., and Miyakawa, T.: Consistency and traceability of black carbon measurements made by laser-induced incandescence, thermal-optical transmittance, and filter-based photoabsorption techniques, Aerosol Sci. Technol., 45, 295-312, 2011.

Laborde, M., Mertes, P., Zieger, P., Dommen, J., Baltensperger, U., and Gysel, M.: Sensitivity of the Single Particle Soot Photometer to different black carbon types, Atmos. Meas. Tech., 5, 10311043, doi:10.5194/amt-5-1031-2012, 2012.

McFiggans, G., Artaxo, P., Baltensperger, U., Coe, H., Facchini, M. C., Feingold, G., Fuzzi, S., Gysel, M., Laaksonen, A., Lohmann, U., Mentel, T. F., Murphy, D. M., O’Dowd, C. D., Snider, J. R., and Weingartner, E.: The effect of physical and chemical aerosol properties on warm cloud droplet activation, Atmos. Chem. Phys., 6, 2593-2649, doi:10.5194/acp-6-2593-2006, 2006.

Moteki, N. and Kondo, Y.: Effects of mixing state on black carbon measurements by laser-induced incandescence, Aerosol Sci. Technol., 41, 398-417, 2007.

Moteki, N. and Kondo, Y.: Method to measure time-dependent scattering cross sections of particles evaporating in a laser beam, J. Aerosol. Sci., 39, 348-364, 2008.

Moteki, N. and Kondo, Y.: Dependence of laser-induced incandescence on physical properties of black carbon aerosols: measurements and theoretical interpretation, Aerosol Sci. Technol., 44, 663-675, 2010.

Moteki, N., Kondo, Y., and Nakamura, S.: Method to measure refractive indices of small nonspherical particles: Application to black carbon particles, J. Aerosol. Sci., 41, 513-521, 2010.

Nakayama, T., Matsumi, Y., Sato, K., Imamura, T., Yamazaki, A., and Uchiyama, A.: Laboratory studies on optical properties of secondary organic aerosols generated during the photooxidation of toluene and the ozonolysis of $\alpha$-pinene, J. Geophys. Res., 115, D24204, doi:10.1029/2010JD014387, 2010.

Saathoff, H., Naumann, K. H., Schnaiter, M., Schock, W., Möhler, O., Schurath, U., Weingartner, E., Gysel, M., and Baltensperger, U.: Coating of soot and $\left(\mathrm{NH}_{4}\right)_{2} \mathrm{SO}_{4}$ particles by ozonolysis products of $\alpha$-pinene, J. Aerosol. Sci., 34, 1297-1321, 2003.

Saathoff, H., Naumann, K.-H., Möhler, O., Jonsson, Å. M., Hallquist, M., Kiendler-Scharr, A., Mentel, Th. F., Tillmann, R., and Schurath, U.: Temperature dependence of yields of secondary organic aerosols from the ozonolysis of $\alpha$-pinene and limonene, Atmos. Chem. Phys., 9, 1551-1577, doi:10.5194/acp-9-15512009, 2009.

Schmid, O., Artaxo, P., Arnott, W. P., Chand, D., Gatti, L. V., Frank, G. P., Hoffer, A., Schnaiter, M., and Andreae, M. O.: Spectral light absorption by ambient aerosols influenced by biomass burning in the Amazon Basin. I: Comparison and field calibration of absorption measurement techniques, Atmos. Chem. Phys., 6, 3443-3462, doi:10.5194/acp-6-3443-2006, 2006.

Schnaiter, M., Linke, C., Möhler, O., Naumann, K. H., Saathoff, H., Wagner, R., Schurath, U., and Wehner, B.: Absorption amplification of black carbon internally mixed with secondary organic aerosol, J. Geophys. Res. Atmos., 110, D19204, doi:10.1029/2005JD006046, 2005.

Schnaiter, M., Gimmler, M., Llamas, I., Linke, C., Jäger, C., and Mutschke, H.: Strong spectral dependence of light absorption by organic carbon particles formed by propane combustion, Atmos. Chem. Phys., 6, 2981-2990, doi:10.5194/acp-6-2981-2006, 2006. 
Schwarz, J. P., Gao, R. S., Fahey, D. W., Thomson, D. S., Watts, L. A., Wilson, J. C., Reeves, J. M., Darbeheshti, M., Baumgardner, D. G., Kok, G. L., Chung, S. H., Schulz, M., Hendricks, J., Lauer, A., Karcher, B., Slowik, J. G., Rosenlof, K. H., Thompson, T. L., Langford, A. O., Loewenstein, M., and Aikin, K. C.: Single-particle measurements of midlatitude black carbon and light-scattering aerosols from the boundary layer to the lower stratosphere, J. Geophys. Res., 111, D16207, doi:10.1029/2006JD007076, 2006.

Schwarz, J. P., Gao, R. S., Spackman, J. R., Watts, L. A., Thomson, D. S., Fahey, D. W., Ryerson, T. B., Peischl, J., Holloway, J. S., Trainer, M., Frost, G. J., Baynard, T., Lack, D. A., de Gouw, J. A., Warneke, C., and Del Negro, L. A.: Measurement of the mixing state, mass, and optical size of individual black carbon particles in urban and biomass burning emissions, Geophys. Res. Lett., 35, L13810, doi:10.1029/2008GL033968, 2008.

Schwarz, J. P., Spackman, J. R., Gao, R. S., Perring, A. E., Cross, E., Onasch, T. B., Ahern, A., Wrobel, W., Davidovits, P., Olfert, J., Dubey, M. K., Mazzoleni, C., and Fahey, D. W.: The detection efficiency of the single particle soot photometer, Aerosol Sci. Technol., 44, 612-628, 2010.

Shindell, D., Kuylenstierna, J. C. I., Vignati, E., van Dingenen, R., Amann, M., Klimont, Z., Anenberg, S. C., Muller, N., JanssensMaenhout, G., Raes, F., Schwartz, J., Faluvegi, G., Pozzoli, L., Kupiainen, K., Höglund-Isaksson, L., Emberson, L., Streets, D., Ramanathan, V., Hicks, K., Oanh, N. T. K., Milly, G., Williams, M., Demkine, V., and Fowler, D.: Simultaneously mitigating near-term climate change and improving human health and food security, Science, 335, 183-189, 2012.
Slowik, J. G., Cross, E. S., Han, J. H., Davidovits, P., Onasch, T. B., Jayne, J. T., WilliamS, L. R., Canagaratna, M. R., Worsnop, D. R., Chakrabarty, R. K., Moosmüller, H., Arnott, W. P., Schwarz, J. P., Gao, R. S., Fahey, D. W., Kok, G. L., and Petzold, A.: An inter-comparison of instruments measuring black carbon content of soot particles, Aerosol Sci. Technol., 41, 295314, 2007.

Stephens, M., Turner, N., and Sandberg, J.: Particle identification by laser-induced incandescence in a solid-state laser cavity, Appl. Optics, 42, 3726-3736, 2003.

Sutherland, R. A., Khanna, R. K., and Ospina, M. J.: Infrared properties of atmospheric aerosol constituents - polyaromatic hydrocarbons and terpenes, Aerosol Sci. Technol., 20, 62-70, 1994.

Wagner, R., Linke, C., Naumann, K. H., Schnaiter, M., Vragel, M., Gangl, M., and Horvath, H.: A review of optical measurements at the aerosol and cloud chamber AIDA, J. Quant. Spectrosc. Ra., 110, 930-949, 2009. 